\title{
Three-dimensional Ultrasound in Detection of Fetal Anomalies
}

\author{
${ }^{1}$ Ritsuko K Pooh, ${ }^{2}$ Asim Kurjak
}

\begin{abstract}
In the history of 3D/4D ultrasound technology, the great achievement was high definition (HD) live technology. This technology is a novel ultrasound technique that improves the 3D/4D images. HDlive ultrasound has resulted in remarkable progress in visualization of early embryos and fetuses and in the development of sonoembryology. HDlive uses an adjustable light source and software that calculates the propagation of light through surface structures in relation to the light direction. The virtual light source produces selective illumination, and the respective shadows are created by the structures where the light is reflected. This combination of light and shadows increases depth perception and produces remarkable images that are more natural than those obtained with classic three-dimensional (3D) ultrasound. The virtual light can be placed in the front, back, or lateral sides, where viewing is desired until the best image is achieved. A great advantage is that the soft can be applied to all images stored in the machine's memory. With HDlive ultrasound, both structural and functional developments can be assessed from early pregnancy more objectively and reliably and, indeed, the new technology has moved embryology from postmortem studies to the in vivo environment. Practically, in obstetrical ultrasound, HDlive could be used during all three trimesters of pregnancy.

Keywords: Fetal abnormalities, Three-dimensional HD silhouette ultrasound, Three-dimensional sonography, Prenatal diagnosis.
\end{abstract}

How to cite this article: Pooh RK, KurjakA. Three-dimensional Ultrasound in Detection of Fetal Anomalies. Donald School J Ultrasound Obstet Gynecol 2016;10(3):214-234.

Source of support: Nil

Conflict of interest: None

\section{RECENT ADVANCES OF 3D ULTRASONOGRAPHY}

Recent advances of 3D/4D sonography have assessed not only structural but also functional early human development. ${ }^{4}$ The three-dimensional (3D) images of embryos were generated using a high-frequency transducer. Demonstration of an embryo of less than $10 \mathrm{~mm}$ (greatest length) has been difficult in the past and not

${ }^{1}$ President, ${ }^{2}$ Professor and President

${ }^{1}$ CRIFM Clinical Research Institute of Fetal Medicine PMC Tennoji, Osaka, Japan

${ }^{2}$ Department of Obstetrics and Gynecology, International Academy of Perinatal Medicine, Zagreb, Croatia

Corresponding Author: Ritsuko K Pooh, CRIFM Clinical Research Institute of Fetal Medicine PMC, Tennoji, Osaka Japan, Phone: +81667758111, e-mail: pooh27ritsuko@fetalmedicine-pooh.com

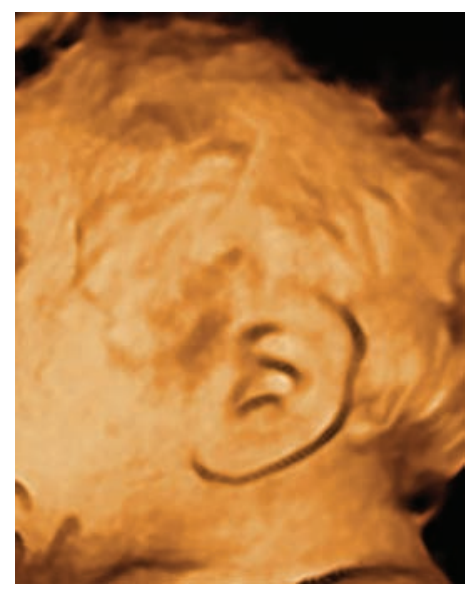

Fig. 1: Normal ear and hair at 35 weeks of gestation by 3D surface rendering

visualized in detail ${ }^{5-7}$. The 3D/4D sonography moved prenatal diagnosis of fetal anomalies from the second to the first trimester of pregnancy. ${ }^{8}$ In the second and third trimesters, 3D ultrasound imaging provides us the detailed superficial structure, such as external ear and hair, as shown in Figure 1. The detailed structure of small parts, for instance, the lenses of eyeballs (Fig. 2) can be visualized by 3D orthogonal view. The 3D ultrasound technology will contribute to demonstration of in utero pathological changes of congenital diseases arising in utero. This can be accomplished through the use of not only surface rendered imaging but also three orthogonal planes, and tomographic ultrasound imaging. Serial examinations allow obtaining exactly the same cutting section at different stages of fetal development. Therefore, it is possible to document the changes of development from early embryonic period.

In the history of 3D/4D ultrasound technology, the great achievement was high definition (HD) live technology. ${ }^{1}$ This technology is a novel ultrasound technique that improves the $3 \mathrm{D} / 4 \mathrm{D}$ images. HDlive ultrasound has resulted in remarkable progress in visualization of early embryos and fetuses and in the development of sonoembryology. ${ }^{2}$ HDlive uses an adjustable light source and software that calculates the propagation of light through surface structures in relation to the light direction. ${ }^{3}$ The virtual light source produces selective illumination, and the respective shadows are created by the structures where the light is reflected. This combination of light and shadows increases depth perception and produces remarkable 


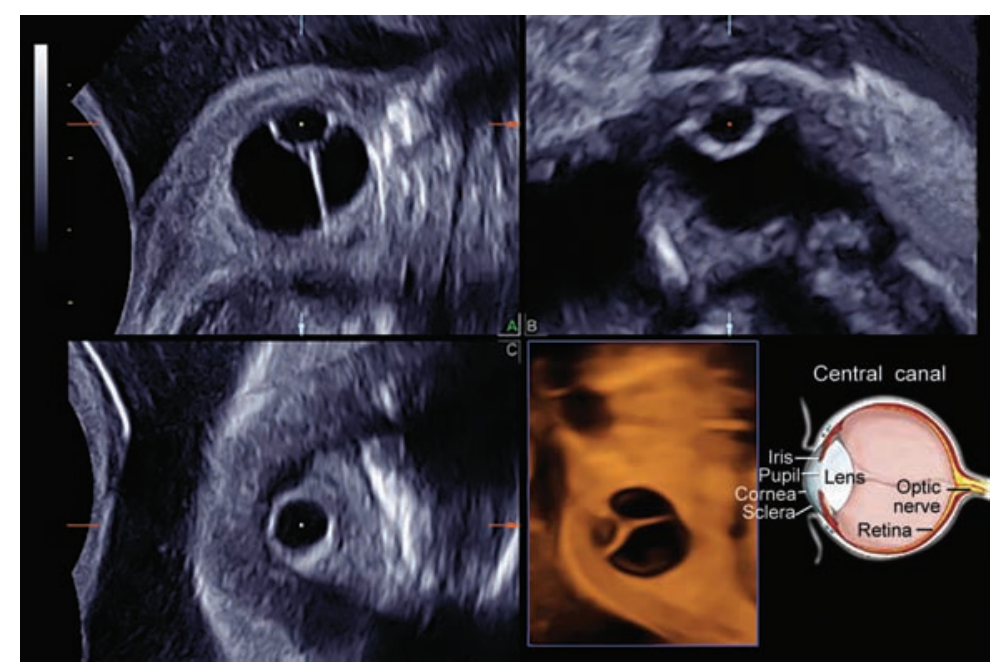

Fig. 2: Eyeball structure at 20 weeks. Three orthogonal view and reconstruction image of the eyeball. Lens and central canal are clearly demonstrated

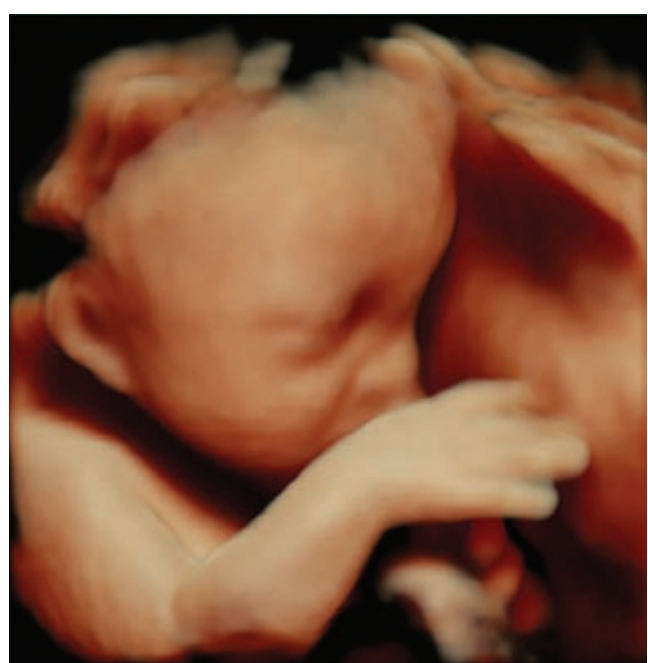

Fig. 3: Normal fetal face and hand at 30 weeks of gestation by 3D HDlive imaging images that are more natural than those obtained with classic 3D ultrasound. The virtual light can be placed in the front, back, or lateral sides, where viewing is desired until the best image is achieved. A great advantage is that the soft can be applied to all images stored in the machine's memory. ${ }^{2}$ With HDlive ultrasound, both structural and functional developments can be assessed from early pregnancy more objectively and reliably and, indeed, the new technology has moved embryology from postmortem studies to the in vivo environment. Practically, in obstetrical ultrasound, HDlive could be used during all three trimesters of pregnancy. As shown in Figures 3, 4A and B, HDlive image of the fetus is more clearly demonstrated by shadowing with virtual light than classic 3D image. There have been several reports on HDlive demonstration of fetal surface. ${ }^{9-12}$ Three-dimensional HDlive further "humanizes" the fetus, enables detailed observation of detailed facial appearance even in the first trimester, and reveals that a small fetus is not a fetus but a "person" with its personality from the first trimester. ${ }^{11}$ Detailed structural abnormalities of face, fingers, toes, and even amniotic membranes in the first trimester could be well demonstrated by HDlive technique. ${ }^{11,12}$ New applications of HDlive silhouette and

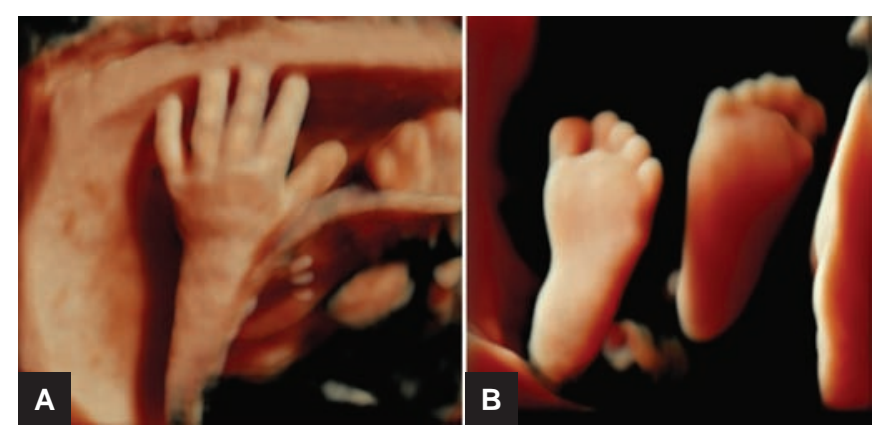

Figs 4A and B: Normal fetal limbs at 19 weeks of gestation by 3D HDlive imaging
HDlive flow were released at the end of 2014. The algorithm of HDlive silhouette creates a gradient at organ boundaries, fluid-filled cavity, and vessels walls, where an abrupt change of the acoustic impedance exists within tissues. ${ }^{13,14}$ By HDlive silhouette mode, an inner cystic structure with fluid collection can be depicted through the outer surface structure of the body and it can be appropriately named as "see-through fashion". ${ }^{13}$

\section{PRENATAL DIAGNOSIS OF ANATOMICAL CONGENITAL ANOMALIES}

The prenatal diagnosis of congenital anomalies with ultrasound is based upon identification of a substantial departure of normal anatomy. This has been possible in the second and third trimesters of pregnancy, and this achievement has made the diagnosis of congenital anomalies one of the objectives of modern prenatal care.

\section{Facial Anomalies}

A facial anomaly can be associated with a central nervous system anomaly, be an isolated finding, or part of a syndrome. Micrognathia (Figs 5A and B) can be
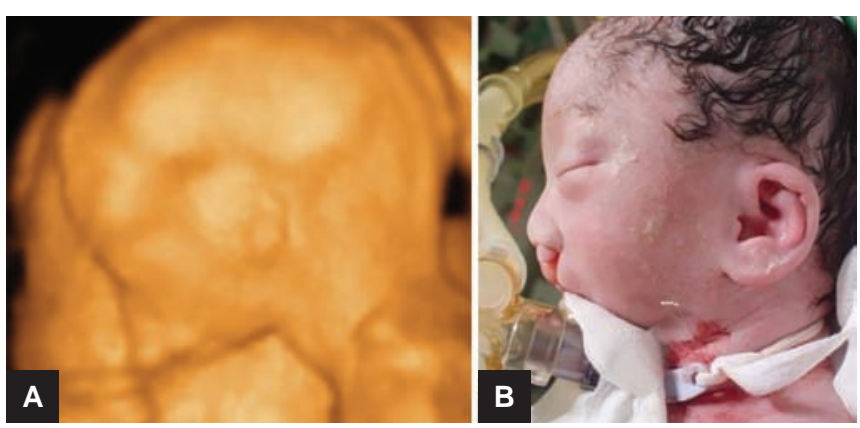

Figs 5A and B: Agnathia with cleft lip at 19 weeks. (Left) 3D reconstructed lateral image of the fetal face at 19 weeks. (Right) Postnatal facial appearance 


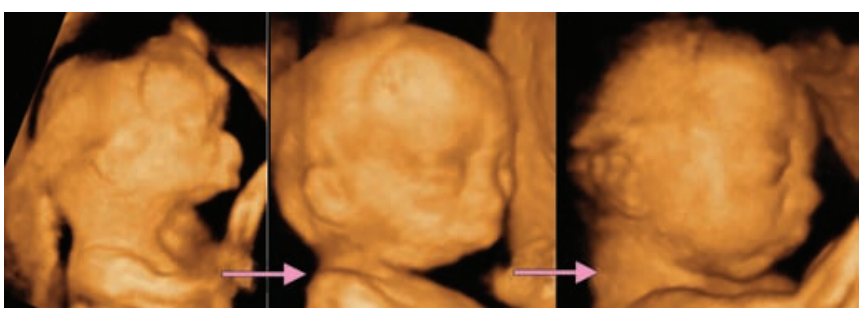

Fig. 6: Slow jaw development in a case of Pierre Robin sequence during pregnancy. Serial 3D scan clearly reveals slow jaw development at 17 weeks (left), 20 weeks (middle), and 29 weeks (right) associated with Pierre Robin sequence

detected as an isolated structural anomaly, as one of the features of a chromosomal abnormality, or a syndrome. ${ }^{15}$ Figure 6 demonstrates the slow jaw development during pregnancy in a case of Pierre Robin sequence, detected by serial 3D ultrasound scans. Congenital micrognathia and lowest ears are frequently detected together as shown in Figure 7, in cases with chromosomal aberrations and other syndromic diseases, because mandible and ears arise from the first pharyngeal (branchial) arch. Assessment of the facial features, chin development, and mandibular size by 3D ultrasound in the second and third trimesters has been reported. ${ }^{16}$ Facial abnormalities are often associated with maldevelopmental brain (Fig. 8) or craniosynostosis (Fig. 9) due to deformed cranial structure. Cleft lip and palate is one of common congenital facial anomalies. Cleft lip occurs unilaterally (Fig. 10) or bilaterally (Figs 11 and 12).

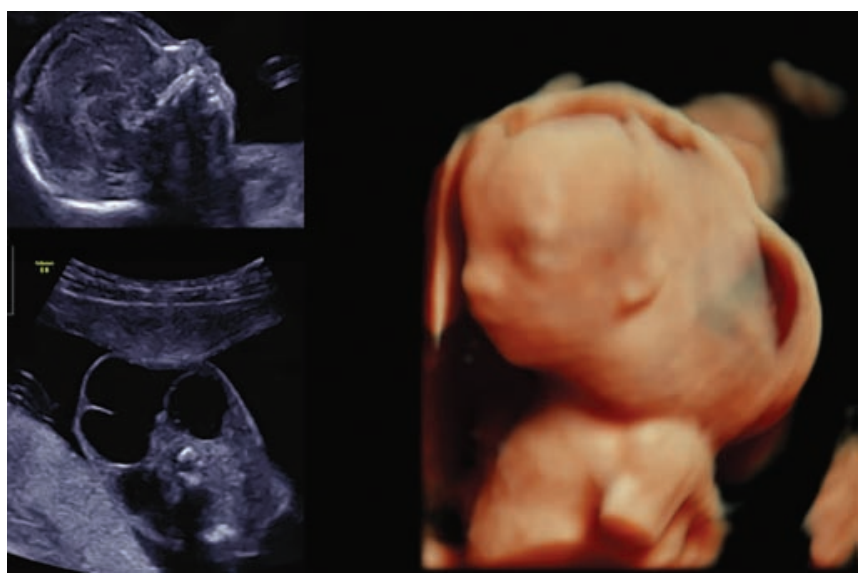

Fig. 7: Low-set ear with micrognathia in a case of cystic hygroma at 18 weeks. Left upper; 2D profile image. Micrognathia is demonstrated. Left lower; 2D image showing cystic hygroma around the neck. Right; HD live image. Low-set ear with micrognathia and dilated neck due to cystic hygroma are demonstrated

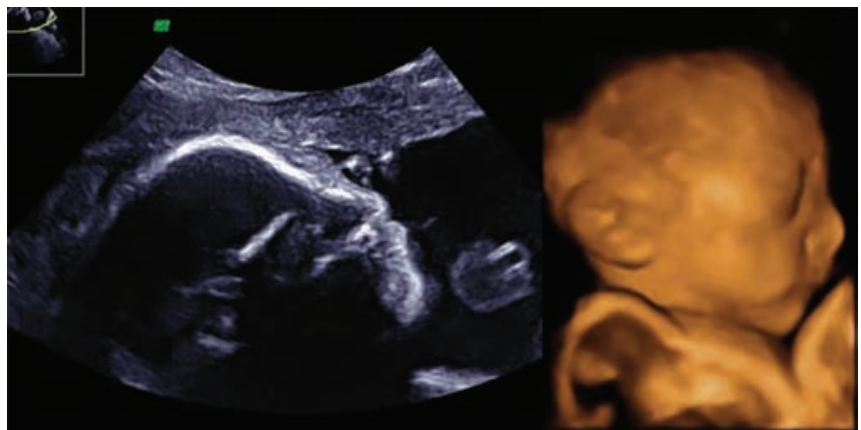

Fig. 8: Face of microcephalic fetus at 23 weeks of gestation. Left; 2D image showing flat face. Right; 3D image
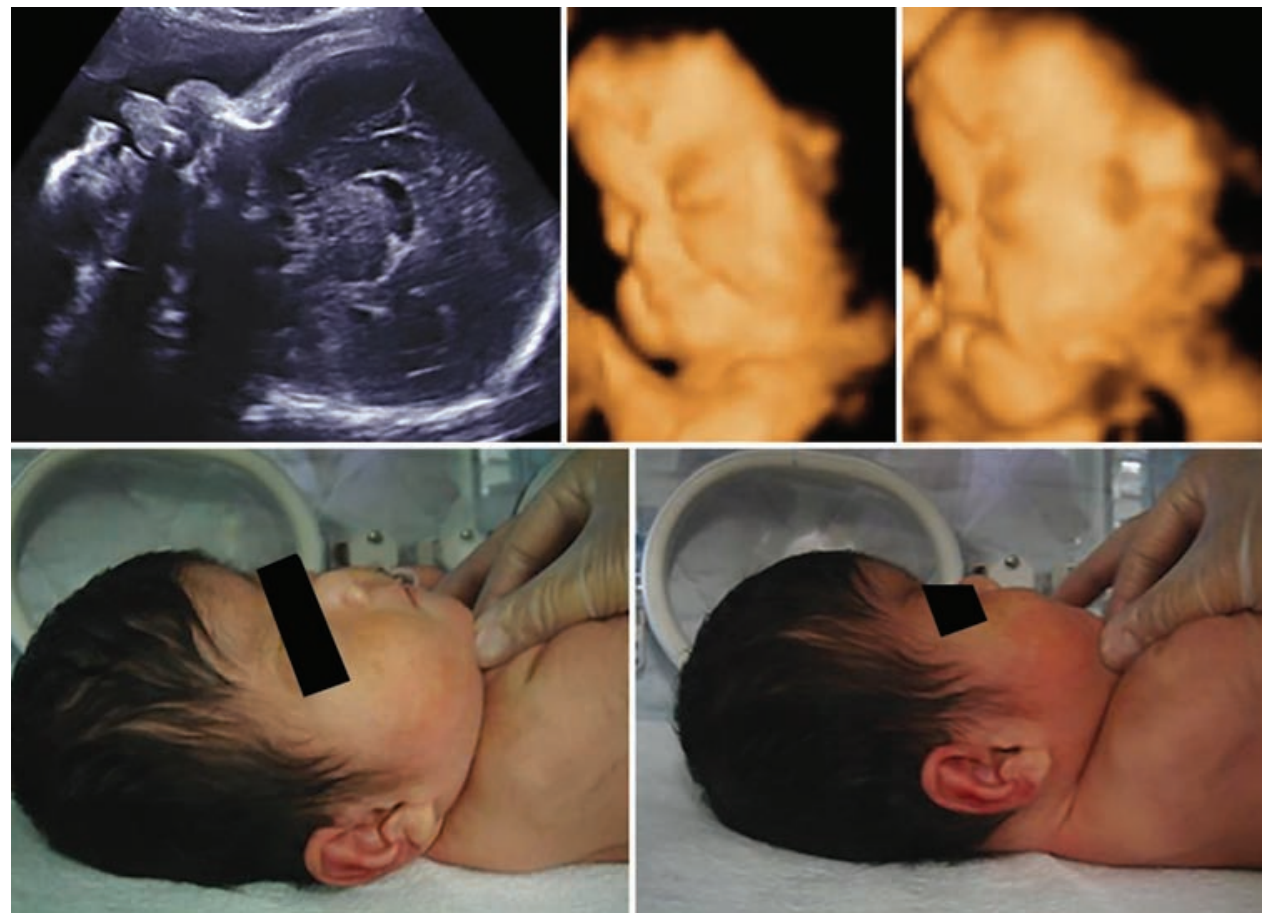

Fig. 9: Facial abnormality associated with Apert syndrome at 31 weeks. (Upper left) 2D sagittal image of the fetal face. Note the marked frontal bossing and low nasal bridge. (Upper middle and right) 3D reconstructed images of fetal face. Exophthalmos is clearly visualized. This facial appearance occurs due to craniosynostosis of coronal sutures seen in a case of Apert syndrome. (Lower pictures) Postnatal facial appearance of the same baby 


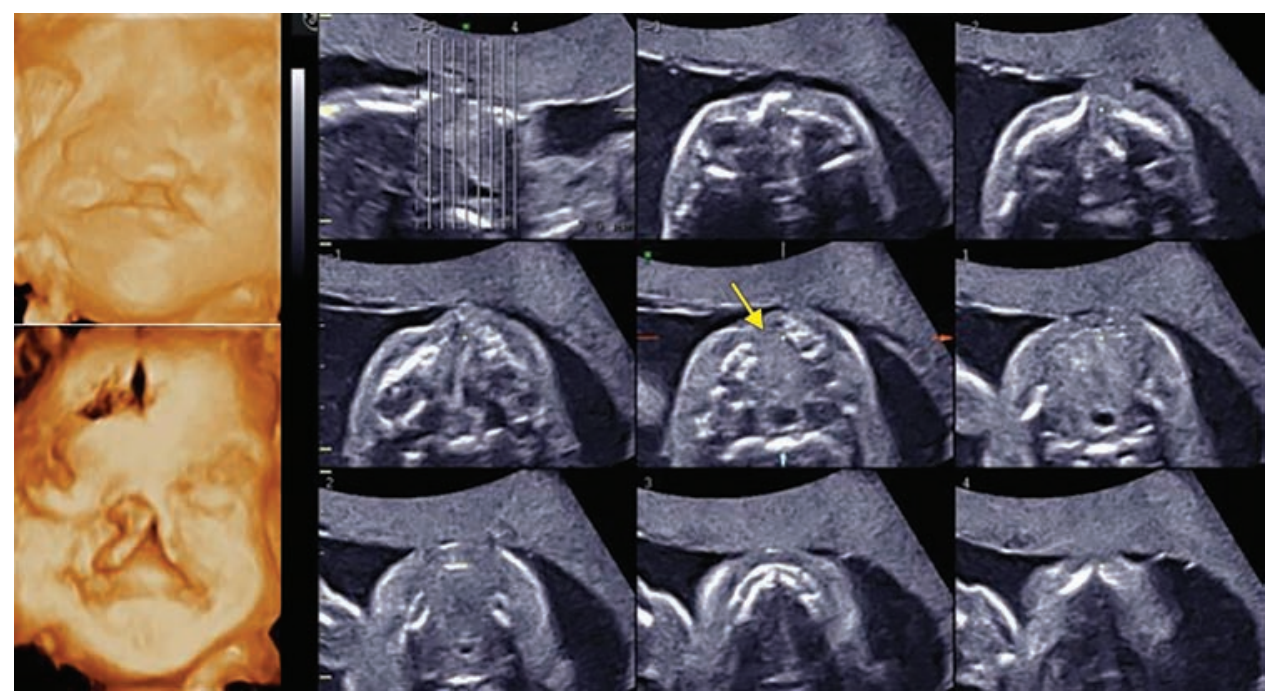

Fig. 10: Cleft lip and palate at 22 weeks. (Upper left) Surface image of the fetal face. Left-sided cleft lip and deformed nasal structure is clearly demonstrated. (Lower left) 3D reconstructed image inside the oral cavity. Cleft palate is visualized. (Right white and black) Tomographic ultrasound image of the anterior maxillary structure, indicating the evidence of alveolar cleft presence (arrow)
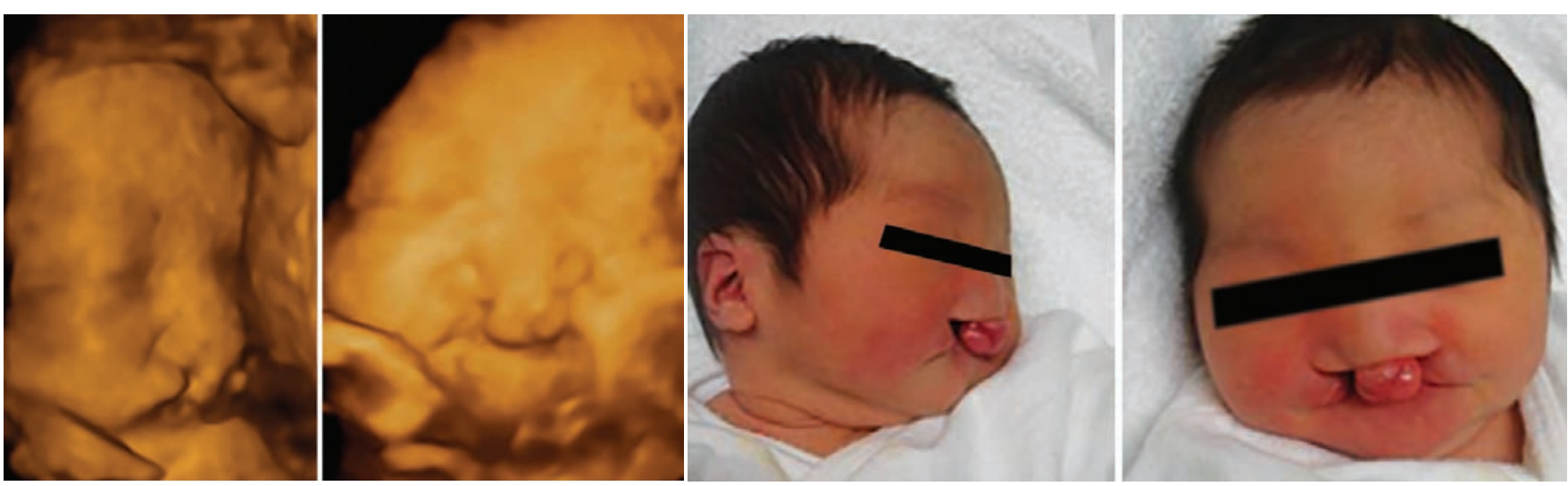

Fig. 11: Bilateral cleft lip at 35 weeks. Bilateral cleft lip is often overlooked because of its symmetrical facial structure. 3D ultrasound shows the clear visualization of the bilateral cleft lip (left figure). Right pictures show postnatal facial appearance of the same baby
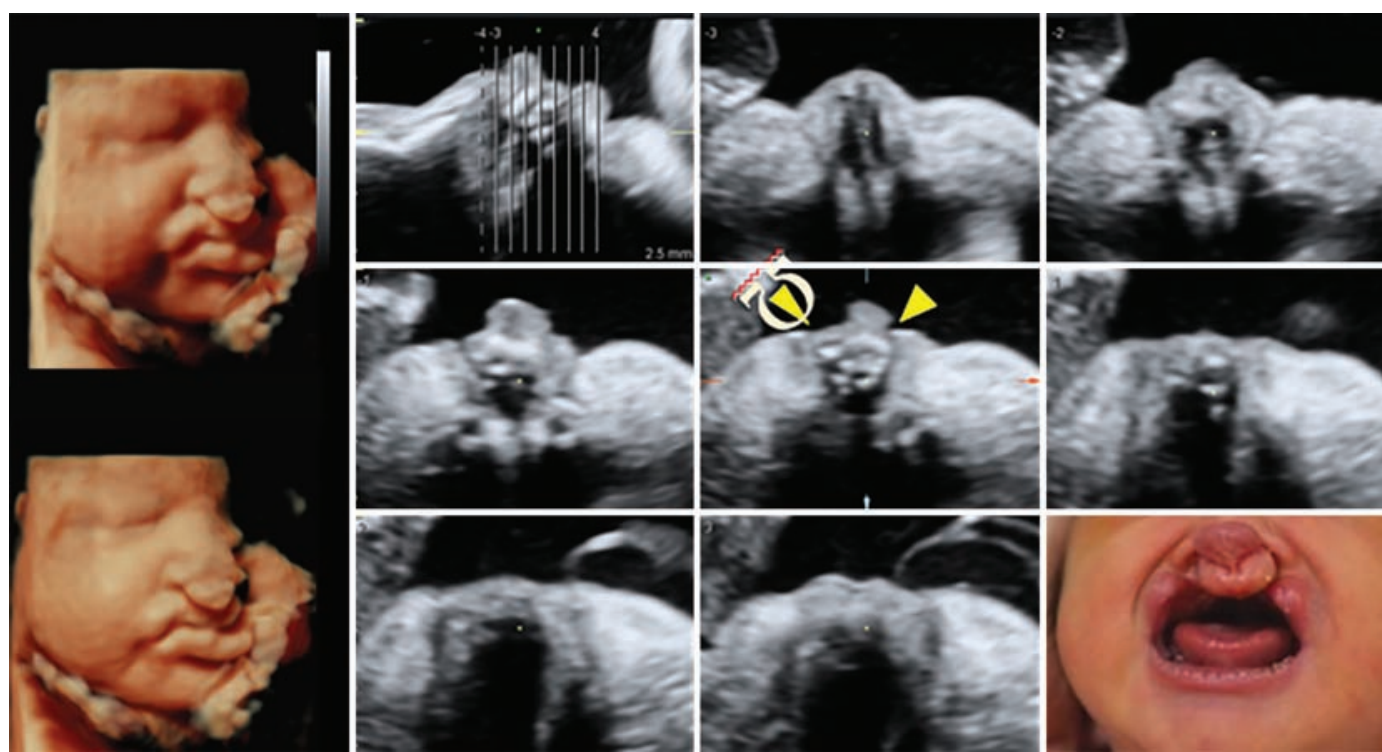

Fig. 12: Bilateral cleft lip/palater at 37 weeks of gestation. Left; HD live images of fetal face. Cleft is very thin and difficult to be detected by surface rendering mode. Right; TUI of lip, alveolus and palate. By tomographic images, narrow cleft lines are bilaterally visible (arrowheads).Right lower; Neonatal cleft lip (Courtesy: Dr. Shimaoka, Shimaoka Clinic, Kyoto, Japan) 


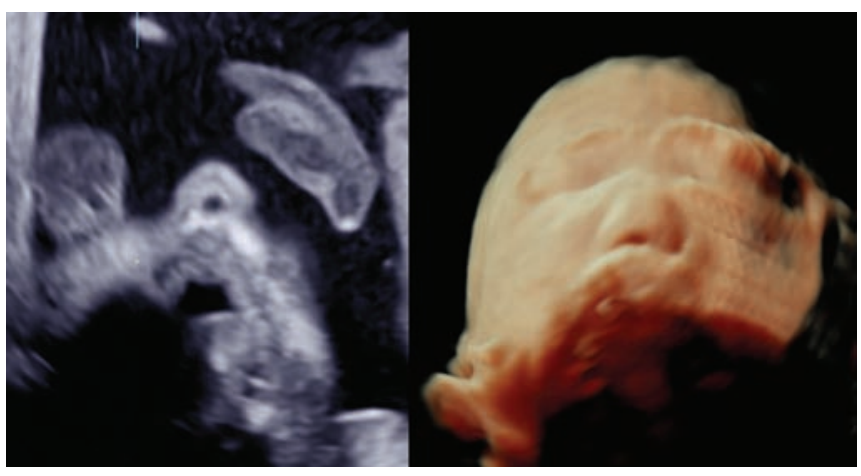

Fig. 13: Single nostril at 20 weeks of gestation in a case of holoprosencephaly. Left; 2D image, Right; 3D HDlive image
Recent 3D tomographic ultrasound can demonstrate anterior maxillary structure, indicating the evidence of alveolar cleft presence shown in the Figures 10 and 12. A single nostril is occasionally seen as demonstrated in Figure 13, associated with holoprosencephaly. Maldevelopment of eyes is often associated with brain abnormalities. Figure 14 shows the holoprosencephalic fetus with cyclops. Three-dimensional ultrasound proved the presence of two eye lenses inside. Exophthalmos and microphthalmia are well demonstrated in Figures 15 and 16 respectively.

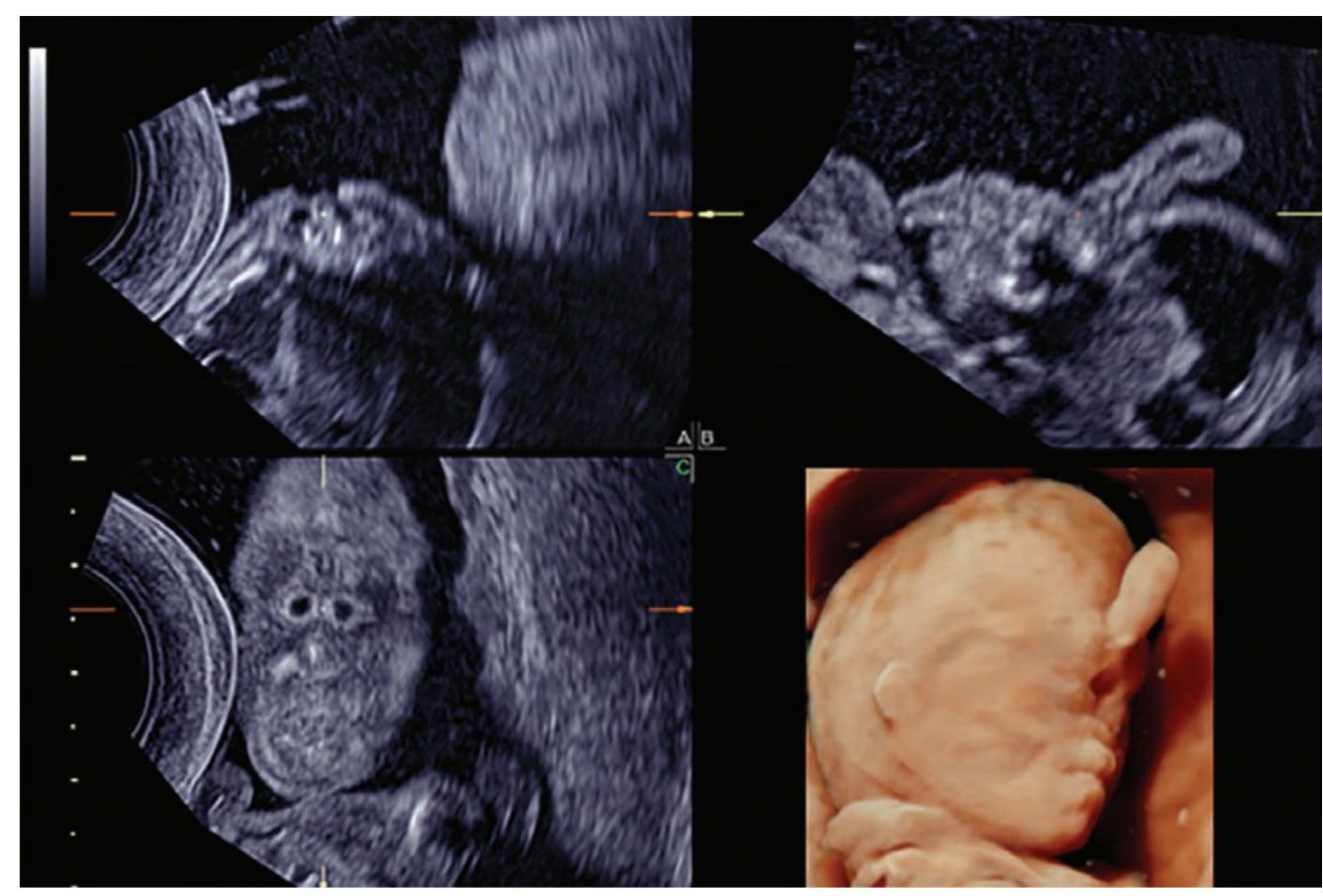

Fig. 14: Two eye lenses seen in a cycloptic eye. Three orthogonal view demonstrates the two eye lenses inside, despite 3D view demonstrates cyclops
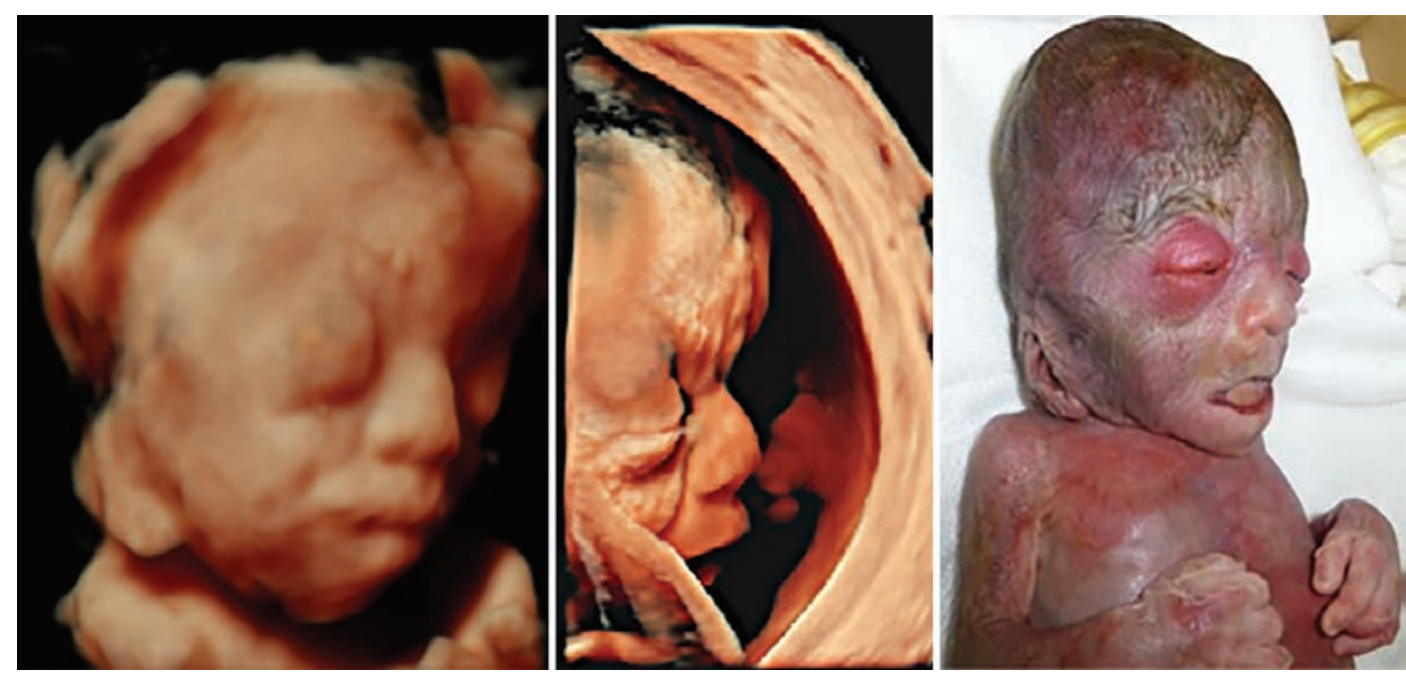

Fig. 15: Exophthalmia, low-set ear, and micrognathia at 23 weeks in a case of multiple anomalies. Left and middle; HD live images showing exophthalmia, low-set ear, and micrognathia. Right; Stillbirth baby. Normal karyotype and the cause was unknown 


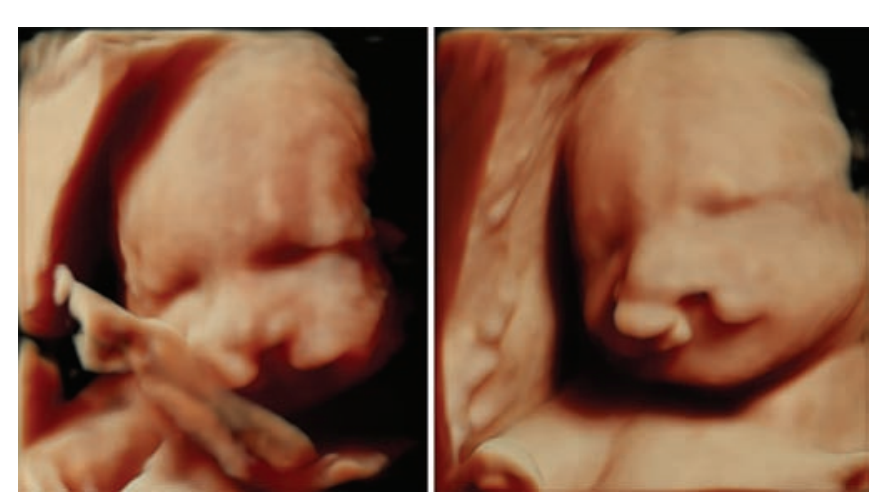

Fig. 16: Microphthalmos and cleft lip seen in a case of trisomy 13

\section{Brain Anomalies}

The brain structure should be understood as a threedimensional structure. ${ }^{17,18}$ Three-dimensional sonographic assessment of premature brain in the early pregnancy was reported from $1995 \cdot{ }^{19,20}$ From 2000, fetal brain assessment in the second and third trimesters by $3 \mathrm{D}$ ultrasound was reported. ${ }^{17,18,21-30}$ Recent advanced 3D ultrasound has enabled to assess detailed brain structure as an understandable organ. Three-dimensional ultrasound abilities, such as tomographic ultrasound imaging and three orthogonal view, greatly contribute to evaluation of fetal brain morphology. ${ }^{29,30}$ Figure 17 shows transvaginal 3D tomographic coronal, sagittal, and axial ultrasound views of intracranial structure in a case of ventriculomegaly at 20 weeks of gestation. Thus, accurate assessment of brain pathology can be done by 3D ultrasound. Furthermore, ventricular appearance can be demonstrated comprehensively by inversion mode, as shown in Figure 18. Cortical development of fetal brain can also be visualized by 3D surface imaging, demonstrating gyral and sulcal development and migration disorder (Fig. 19) which had been difficult to

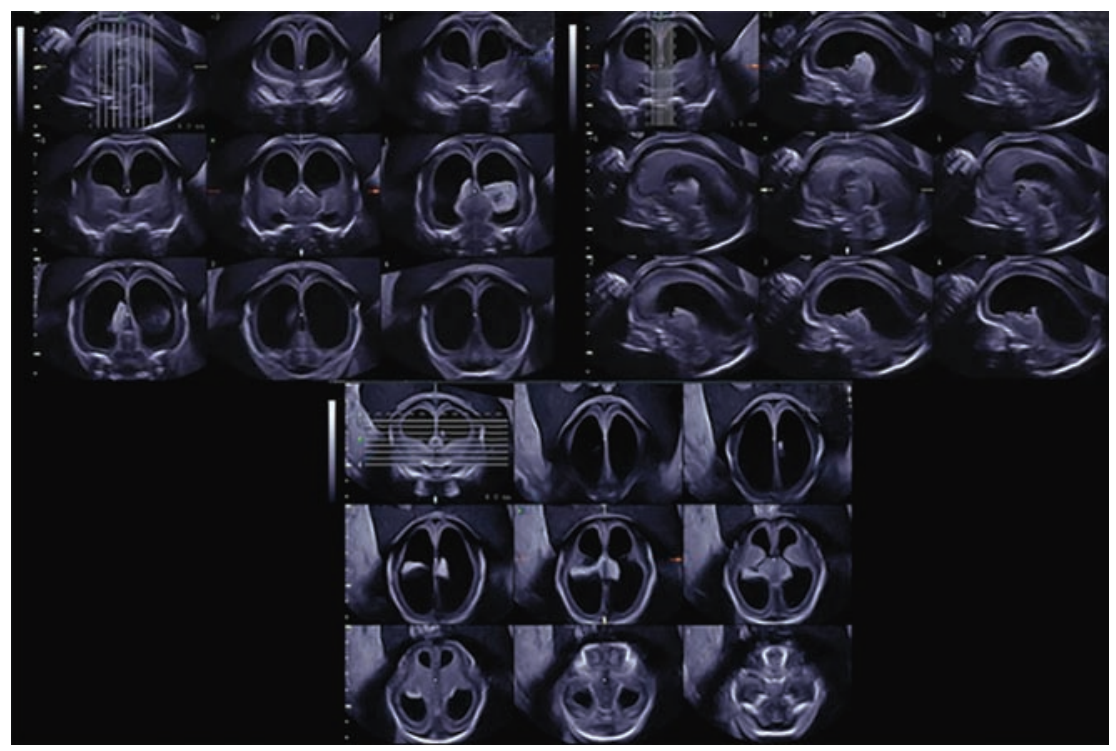

Fig. 17: Hydrocephalus at 20 weeks. Tomographic ultrasound images of coronal (upper left), sagittal (upper right) and axial (lower) views. Clear visualization of intracranial structure is acquired

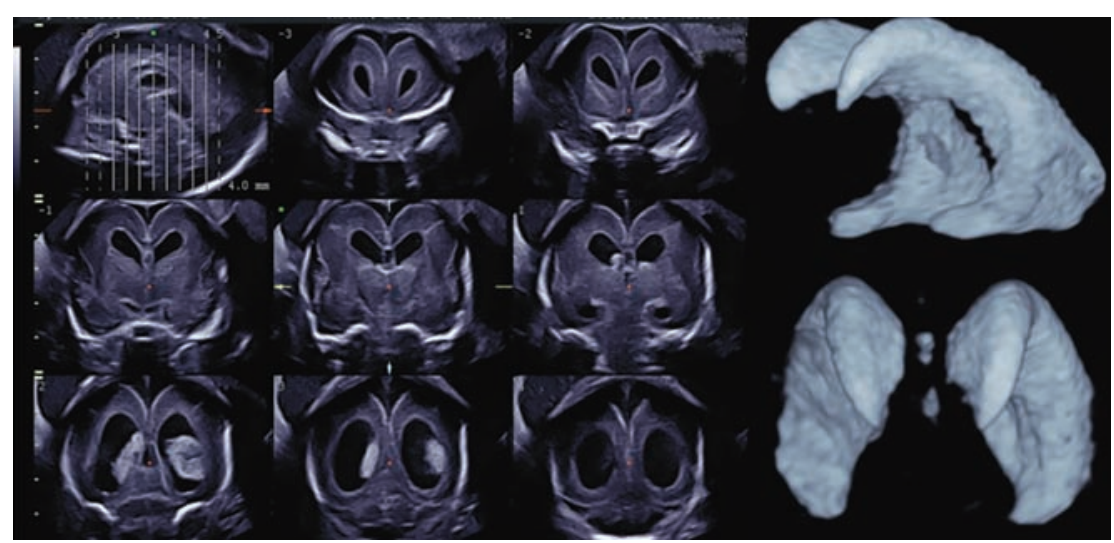

Fig. 18: Ventriculomegaly at 20 weeks. Left picture shows tomographic ultrasound image of coronal section. Right figures demonstrate lateral ventricular appearance by using 3D inversion mode 


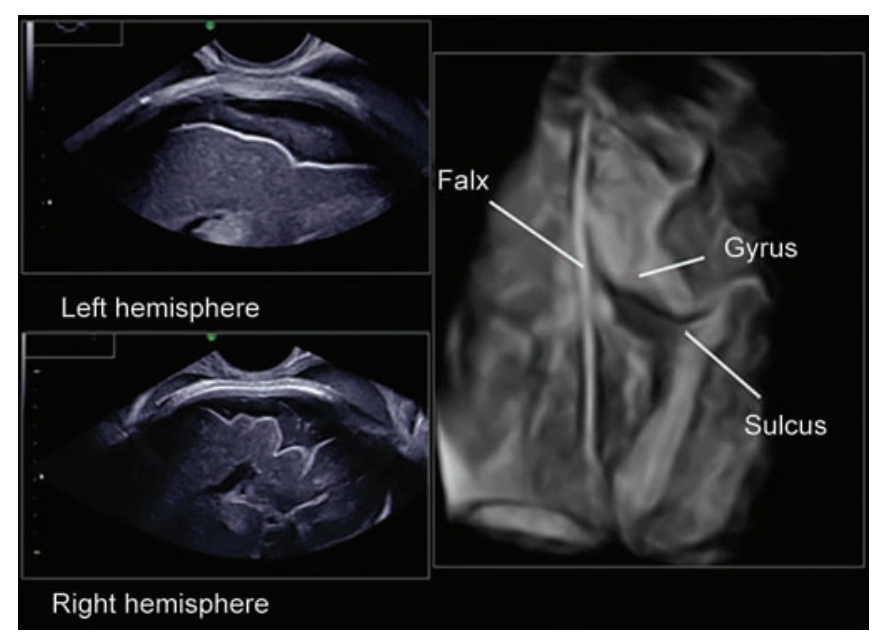

Fig. 19: Asymmetrical cortical formation at 29 weeks. Note the marked difference between left and right cortical appearance (left figures). Right figure demonstrated asymmetrical superficial image of the brain. Clear visualization of the brain surface with asymmetrical gyral/sulcal formation is acquired

be detected during pregnancy, can be depicted by 3D ultrasound. ${ }^{31}$ Figure 13 demonstrates the asymmetrical cortical development due to migration disorder by 2D ultrasound and 3D surface imaging. The 3D volume contrast imaging demonstrated the cortical development (Fig. 20). Thus, 3D ultrasound surface imaging is useful in objective assessment of brain surface. The cranial bone abnormality, seen in a case of encephalocele, can be also visualized by $3 \mathrm{D}$ ultrasound maximum mode imaging as shown in Figure 21.

\section{Vertebra and Spinal Cord Abnormalities}

Spina bifida is the most common anomaly of the central nervous system. It is often detected during the second and third trimesters. However, the fundamental basis for this anomaly is a failure of the neural tube to close during early embryonic age. Most reports of the diagnosis of
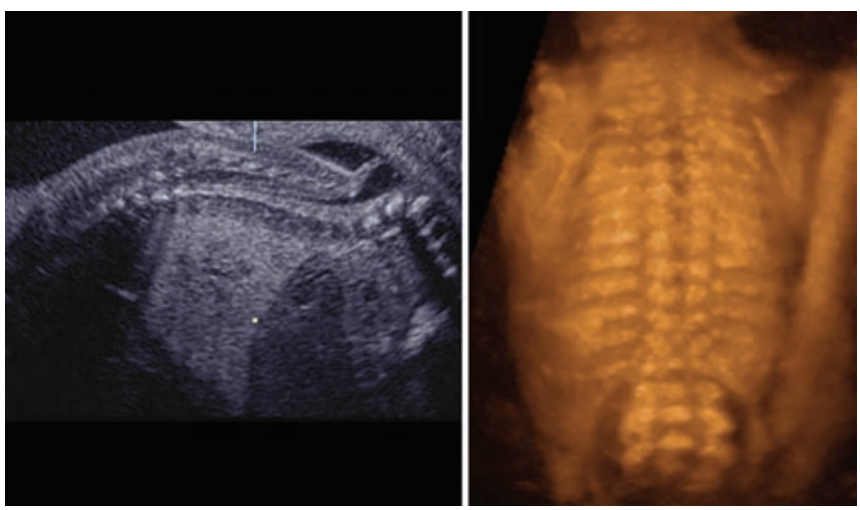

Fig. 22: Myelomeningocele with kyphosis at 20 weeks. (Left) Sagittal image of the fetal trunks from 3D orthogonal view. Severe kyphosis and myelomeningocele is seen. (Right) 3D reconstructed image of the fetal back. The huge mass is seen from $L 1$ to $S$ region. The ribs are clearly seen and the level of spina bifida is easily understandable
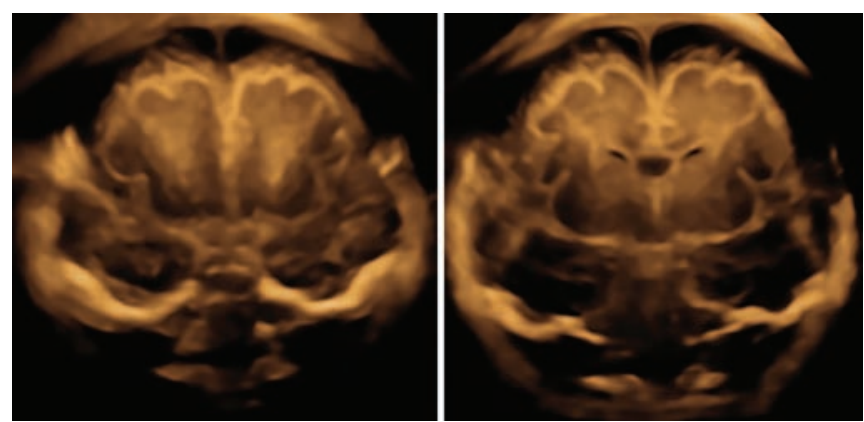

Fig. 20: Hydrocephalus ex-vacuo at 30 weeks. Three-dimensiona volume contrast images demonstrate the cortical development. Note the abnormal large subarachnoid space around the hemispheres
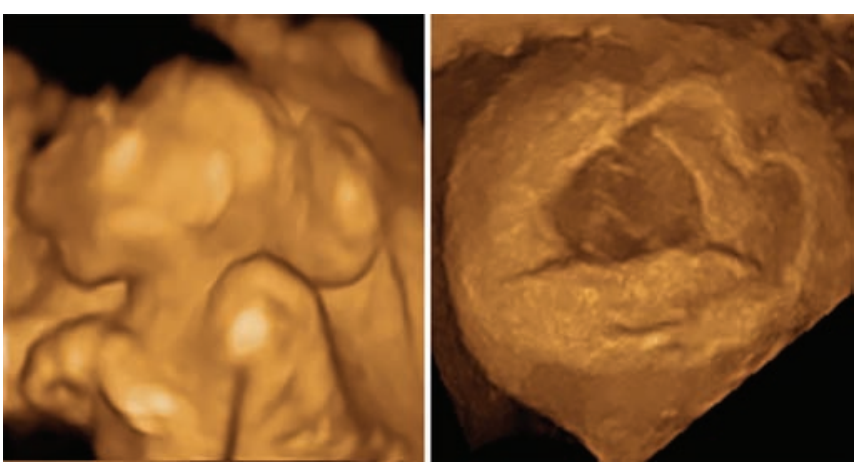

Fig. 21: Encephalocele at 19 weeks. (Left) 3D reconstructed lateral image of the fetus. Microcephaly with encephalocele is clearly demonstrated. (Right) The posteroanterior view of the cranial bones. The round shaped bony defect is demonstrated. S; sagittal suture, L; lambdoid suture

spina bifida in utero have occurred after 12 weeks of gestation. Blaas et $\mathrm{al}^{32}$ reported an early diagnosis using $2 \mathrm{D}$ and 3D ultrasound before 10 weeks of gestation. Figure 22 demonstrates myelomeningocele at 20 weeks. The vertebral bony structure can be depicted by 3D ultrasound for better understanding the level of spina bifida. Vertebral scoliosis is often seen in cases of limb body wall complex (Fig. 23) or cases of hemivertebra, as shown in

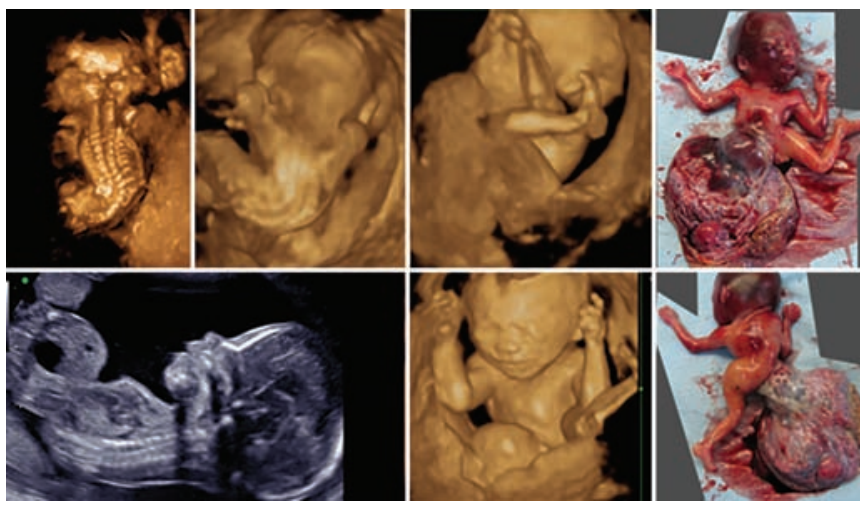

Fig. 23: Vertebral scoliosis associated with limb body wall complex at 20 weeks. Severe vertebral scoliosis, abnormal leg position with one leg missing, Umbilical hernia with short umbilical cord are clearly demonstrated by 2D/3D ultrasound. Right two figures show the appearance of the aborted fetus 

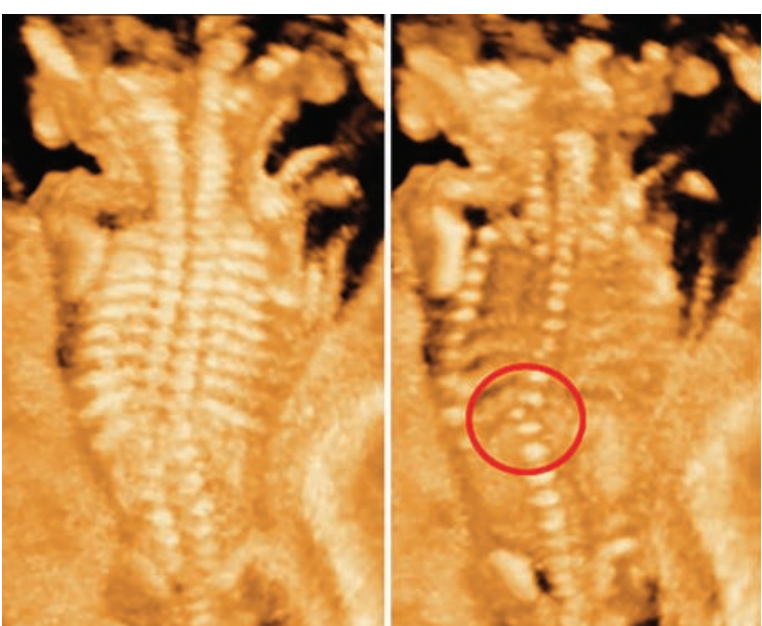

Fig. 24: Hemivertebra at 19 weeks. (Left) 3D maximum mode image of the fetal back. Scoliosis with asymmetrical number of ribs (left; 11 ribs, right; 10 ribs) is clearly demonstrated. (Right) 3D image of the vertebral body layer reveals Th12 hemivertebra (red circle) and this hemivertebra should be the cause of scoliosis
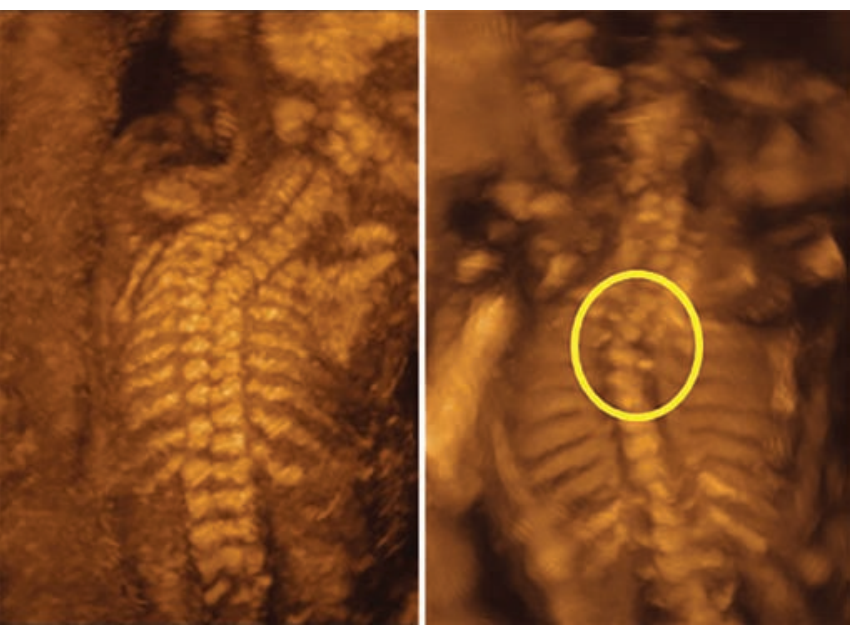

Fig. 25: Three levels hemivertebra at 20 weeks. (Left) 3D maximum mode image of the fetal back. Severe scoliosis with asymmetrical number of ribs (left; 12 ribs, right; 9 ribs) is clearly demonstrated. (Right) 3D image of the vertebral body layer reveals three levels hemivertebrae (Th1-Th3, yellow circle)
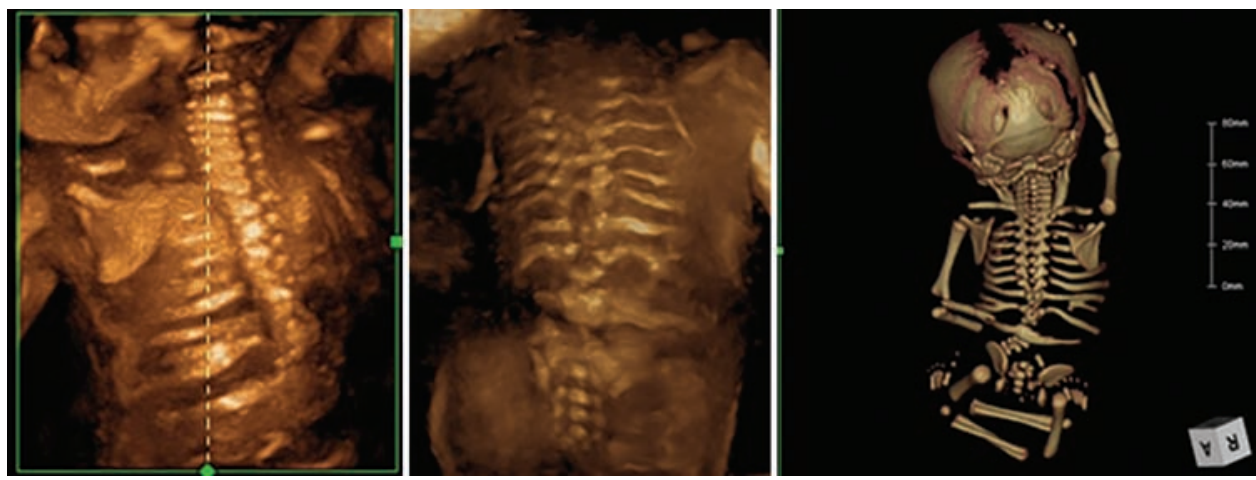

Fig. 26: Segmental spinal dysgenesis at 27 weeks (3D ultrasound and 3D-CT images). (Left and middle) 3D US reconstructed images. Note the focal dysgenesis of the thoracolumbar vertebra, with rib abnormality which indicates features of segmental spinal dysgenesis. (Right) 3D-CT scan image of the same fetus. Clear visualization of the bony structure is acquired

Figures 24 and 25. In hemivertebral cases, asymmetrical rib number can be also demonstrated. Figure 26 shows the segmental spinal dysgenesis, characterized by focal agenesis, or dysgenesis of the lumbar or thoracolumbar spine, with focal abnormality of the underlying spinal cord and nerve roots. ${ }^{33}$

\section{Abdominal Abnormalities}

Ventral body wall defects comprise a group of congenital malformations that include omphalocele (Figs 27 and 28) and gastroschisis (Fig. 29), which are relatively common. Fetal ascites (Figs 30 and 31) is an uncommon abnormality usually in relation to chromosomal abnormality, intrauterine infections, gastrointestinal processes, genitourinary tract abnormalities, or idiopathic causes.

\section{Chest-abdominal Abnormalities}

Differentiation of congenital diaphragmatic hernia (CDH), congenital cystic adenomatoid malformation (CCAM), and diaphragmatic eventration are important. Figure 32 shows schematic pictures of those chest abnormalities.

Congenital diaphragmatic hernia occurs in 1 of every 2,000 to 4,000 live births and accounts for $8 \%$ of all major congenital anomalies. ${ }^{34}$ There are three types of $\mathrm{CDH}$ : posterolateral or Bochdalek hernia (occurring at approximately 6 weeks' gestation), the anterior Morgagni hernia, and a hiatus hernia. The left-sided Bochdalek hernia occurs in approximately $90 \%$ of cases. Left-sided hernias allow herniation of both small and large bowel as well as intraabdominal solid organs into the thoracic cavity. Early diagnosis of $\mathrm{CDH}$ in the first trimester has been reported. ${ }^{35}$ Figure 33 demonstrates 3D image of $\mathrm{CDH}$ liver-up type at 15 weeks and Figure 34 shows the tomographic ultrasound imaging of Bochdalek hernia at 16 weeks. Early diagnosis of this defect is important for the option of fetal treatment. Congenital cystic adenomatoid malformation (Fig. 35) is a benign mass of abnormal lung tissue, located usually on one section of the lung. This condition is caused by overgrowth of abnormal lung 


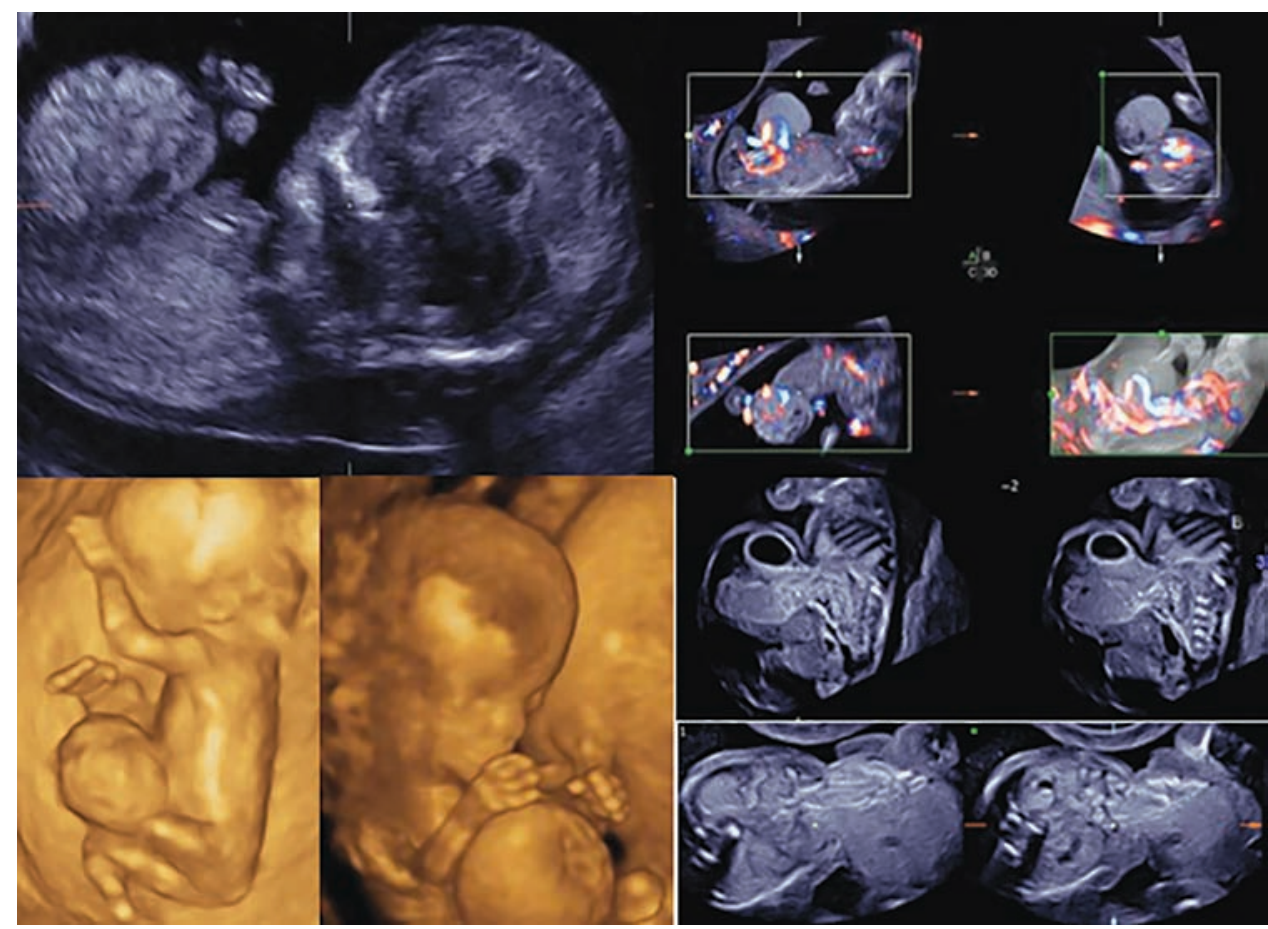

Fig. 27: Huge omphalocele at 12 weeks. (Upper left) Sagittal image from 3D orthogonal view. Increased nuchal translucency is seen. (Upper right) Three orthogonal view and reconstructed image of the fetal circulation. Because of the ectopic liver, the umbilical vein and ductus venosus run outside the body toward the heart inside the body. The ductus venosus reversed flow was seen in this case. (Lower left) 3D reconstructed images. (Lower right) Four selected images from tomographic ultrasound images, demonstrating the relation of ectopic organs and inside organ. After confirming normal chromosome and no other associated anomalies were confirmed, parents decide to continue pregnancy. Postnatal surgery was successful and postoperative course has been favorable

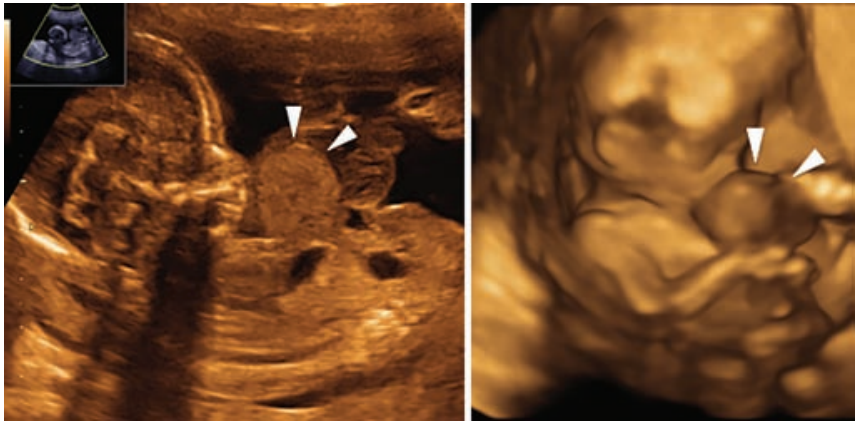

Fig. 28: Omphalocele at 17 weeks. Left; 2D sagittal image. Liver is ectopic (arrowheads) Right; 3D image

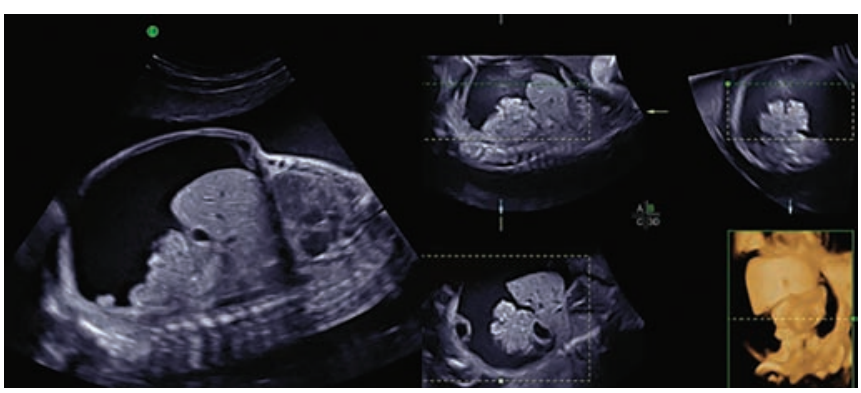

Fig. 30: Severe ascites at 28 weeks. Left; 2D sagittal image demonstrates large amount of ascites. Right; Three orthogonal view with $3 \mathrm{D}$ reconstructed image
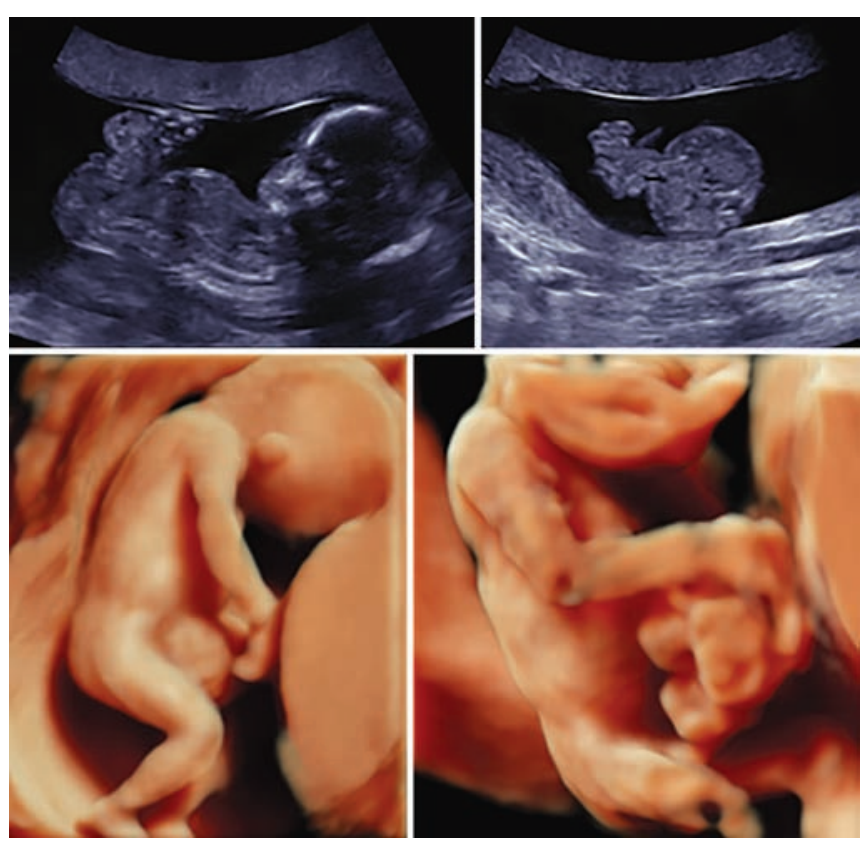

Fig. 29: Gastroschisis at 17 weeks of gestation. Upper; 2D sagitta and axial images. Lower; 3D images. Information from left upper and lower images, it is difficult to differentiate from umbilical hernia. However, it is easy to diagnose gastroschisis from right two figures 
tissue that may form fluid-filled cysts and has no function of normal lung tissue. Early diagnosis of CCAM by 3D ultrasound was reported..$^{36}$ Pleural effusion and ascites (Fig. 36) can be easy diagnosed by both 2D/3D ultrasound
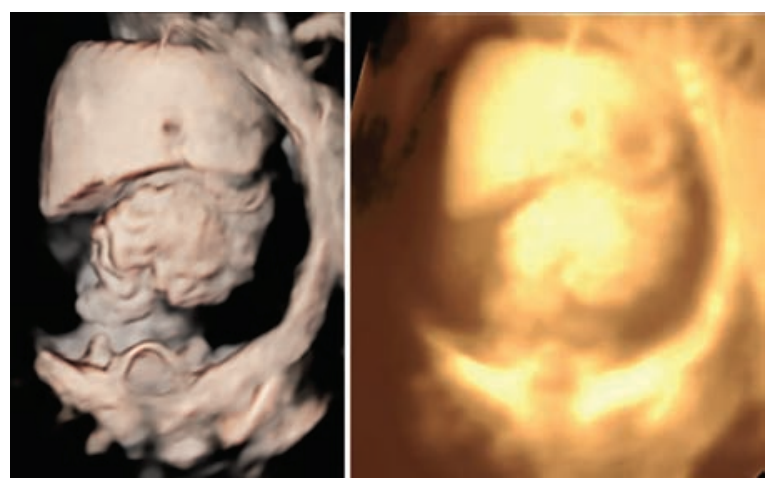

Fig. 31: Three-dimensional images of Intraabdominal organs in a case with severe ascites. Liver, bowels, and bladder are demonstrated technologies. In cases of pleural effusion, the lung is floated inside the fluid, whereas in cases of pericardiac effusion, the lungs are oppressed to posterior portion of the chest (see Fig. 37).

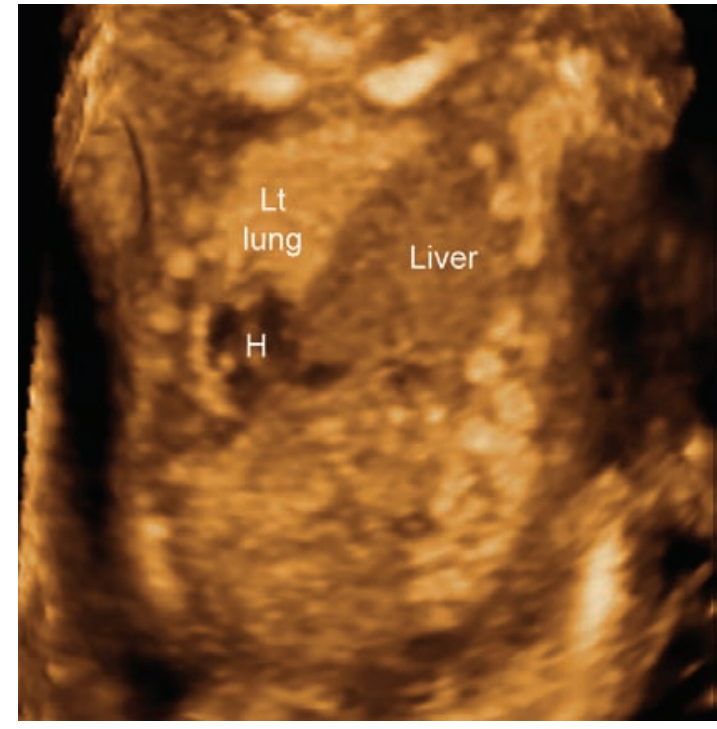

Fig. 33: Congenital diaphragmatic hernia at 15 weeks of gestation. Three-dimensional coronal image. Because of huge defect of left side of diaphragm, liver goes up into the chest and the heart $(\mathrm{H})$ and left lung are oppressed to the right side

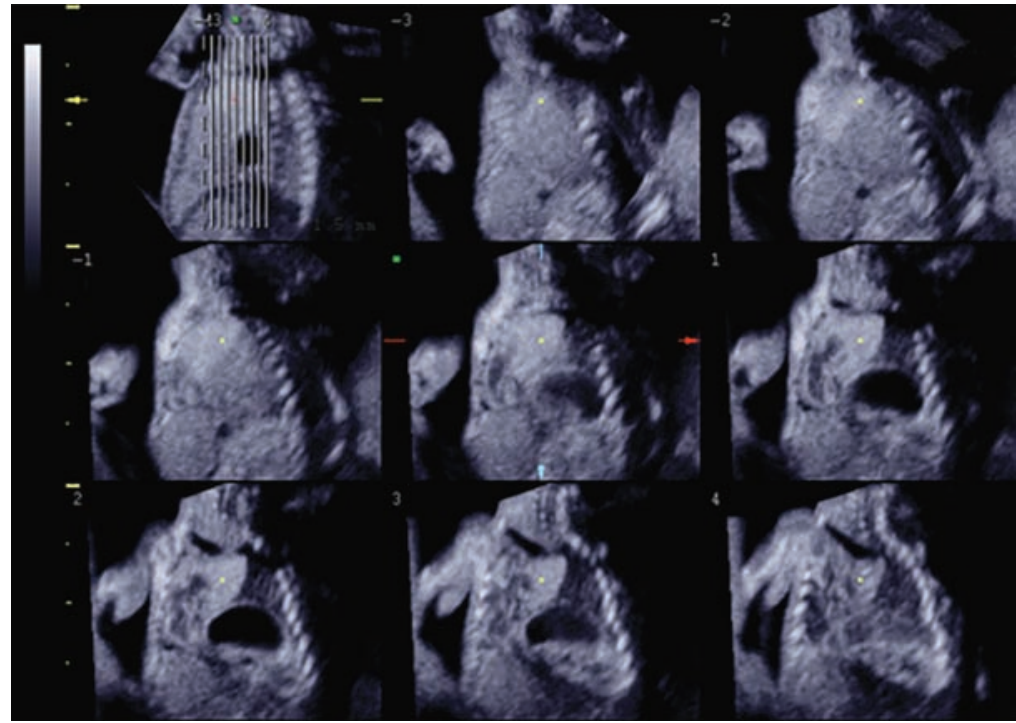

Fig. 34: Congenital diaphragmatic hernia at 16 weeks. Tomographic ultrasound image. Typical Bochdalec hernia is seen. Tomographic image clearly shows oppressed and hypoplastic left lung, heart replacement to the right, and the stomach inside thoracic space

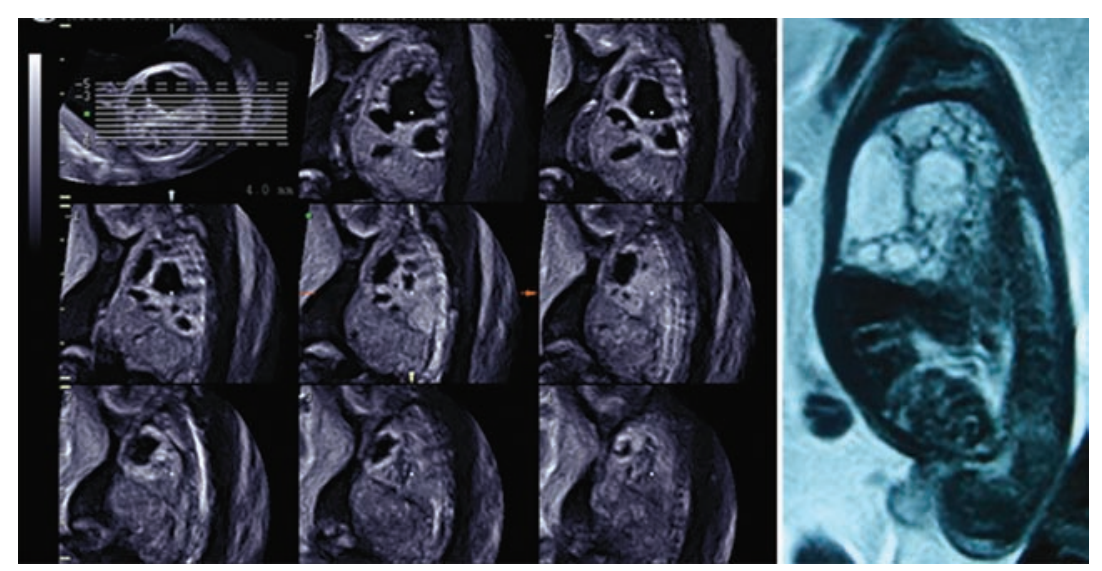

Fig. 35: Congenital cystic adenomatoid malformation (CCAM) at 24 weeks. (Left) Tomographic ultrasound sagittal image of fetal chest. Multiple cysts with different size are seen. (Right) MR image of the same fetus 


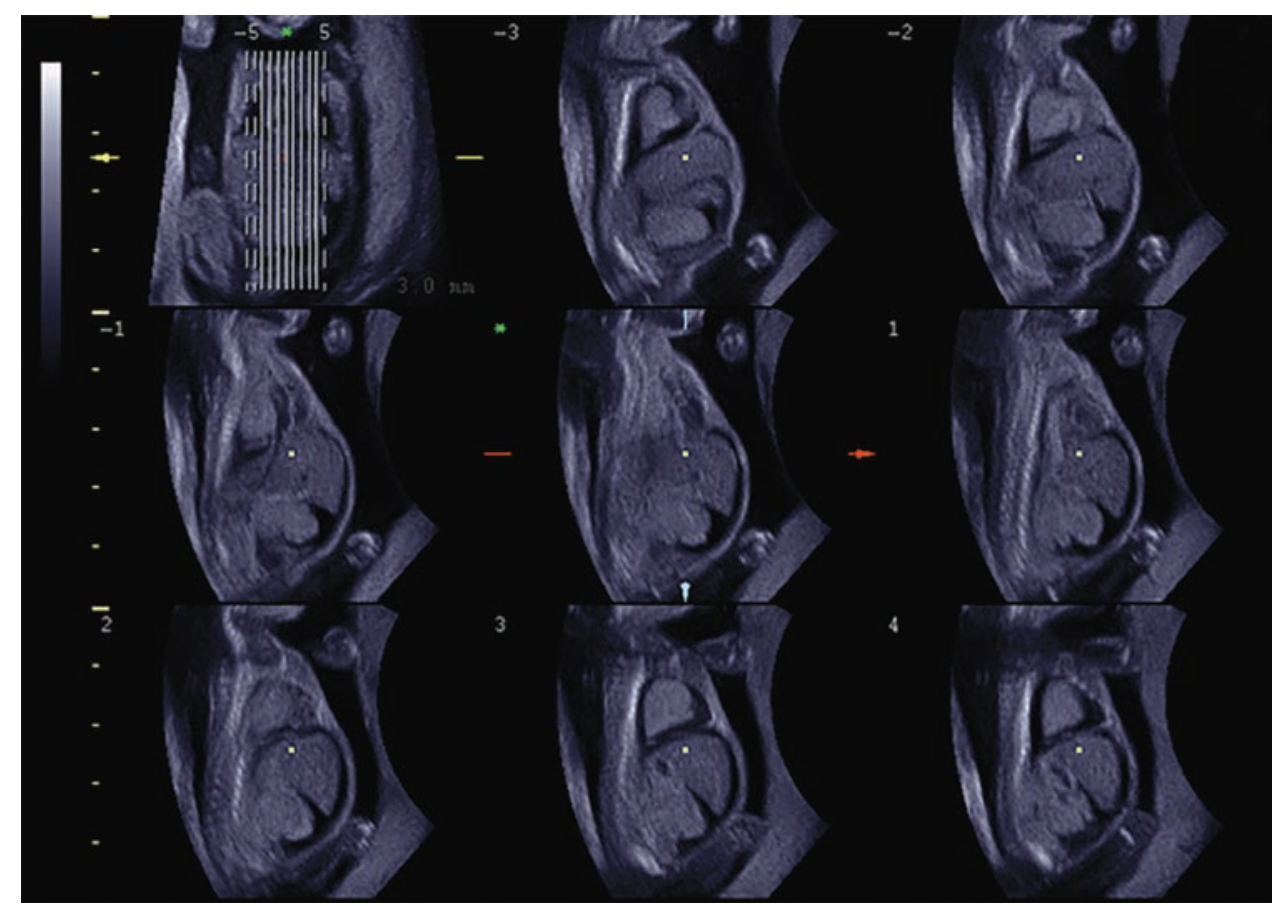

Fig. 36: Pleural effusion and ascites at 19 weeks. Tomographic ultrasound sagittal image of the fetal trunk. Fluid collection in both chest and abdomen are clearly demonstrated

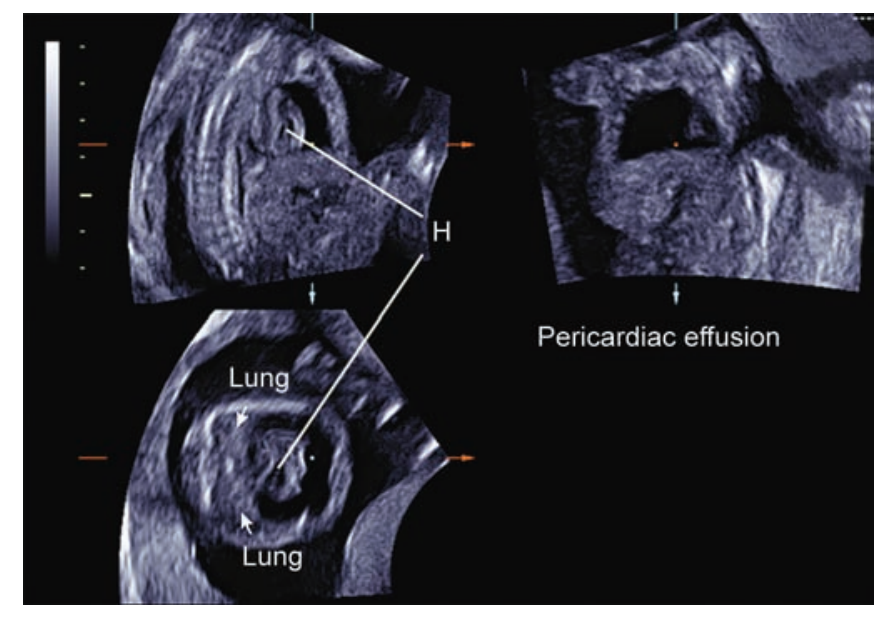

Fig. 37: Pericardiac effusion at 19 weeks. Three orthogonal view of the fetal chest. Due to fluid collection inside epicardium, the lungs are oppressed to posterior potion of the chest. Three orthogonal view (left) and 3D reconstructed inverted image of the renal pelvis (right)

\section{Renal and Urinary Abnormalities}

Hydronephrosis (Fig. 38) occasionally occurs during pregnancy. The causes vary: Obstruction or stenosis of ureters, posterior urethral valves (Figs 39 and 40), or others. The horseshoe kidney is the most common type of renal fusion anomaly. It consists of two distinct functioning kidneys on each side of the midline, connected at the lower poles by an isthmus of functioning renal parenchyma or fibrous tissue that crosses the midline of the body. Figures 41 and 42 demonstrate horseshoe kidney by 2D and 3D ultrasound. Multicystic dysplastic kidney (MCDK, Figs 43 and 44) is a form of renal dysplasia characterized by the presence of multiple cysts of varying size in the kidney and the absence of a normal pelvocaliceal system. Unilateral MCDK is benign and usually no decreased amniotic fluid is seen. However,

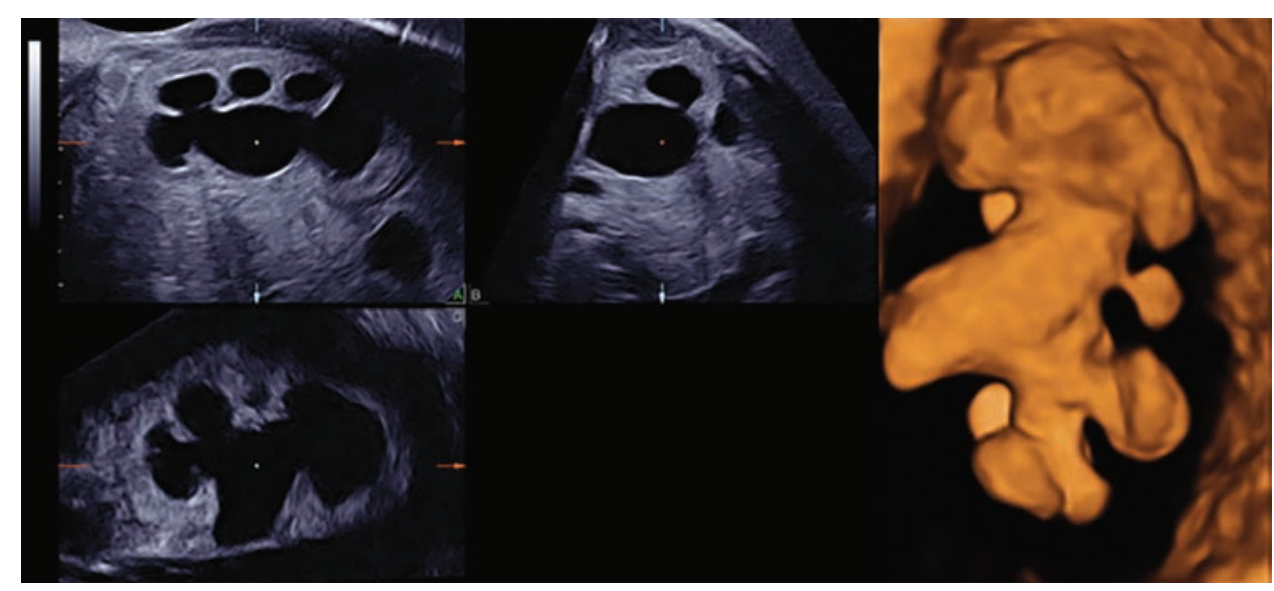

Fig. 38: Mild hydronephrosis at 27 weeks 


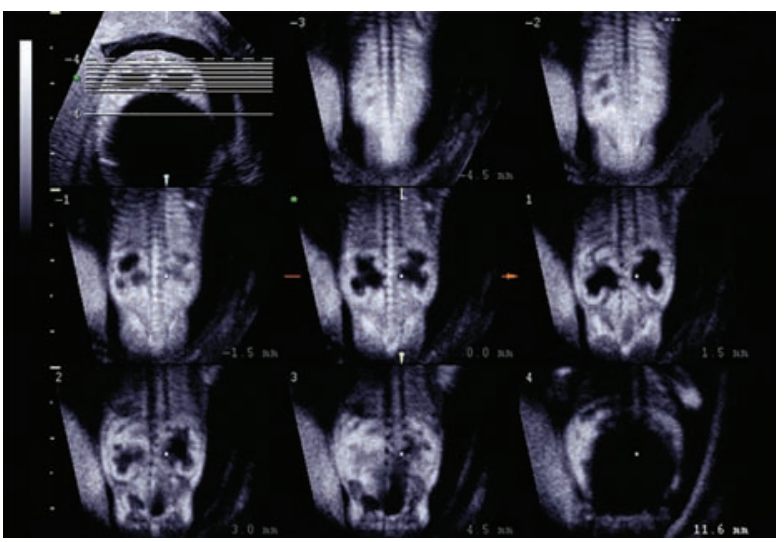

Fig. 39: Bilateral hydronephrosis due to posterior urethral valve stenosis at 15 weeks. Tomographic ultrasound coronal image of the bilateral kidneys. Bilateral hydronephrosis with huge bladder occurred due to poterior urethral valve stenosis. Vesico-amniotic shunt at 17 weeks was successfully performed in this case and postnatal course was favorable
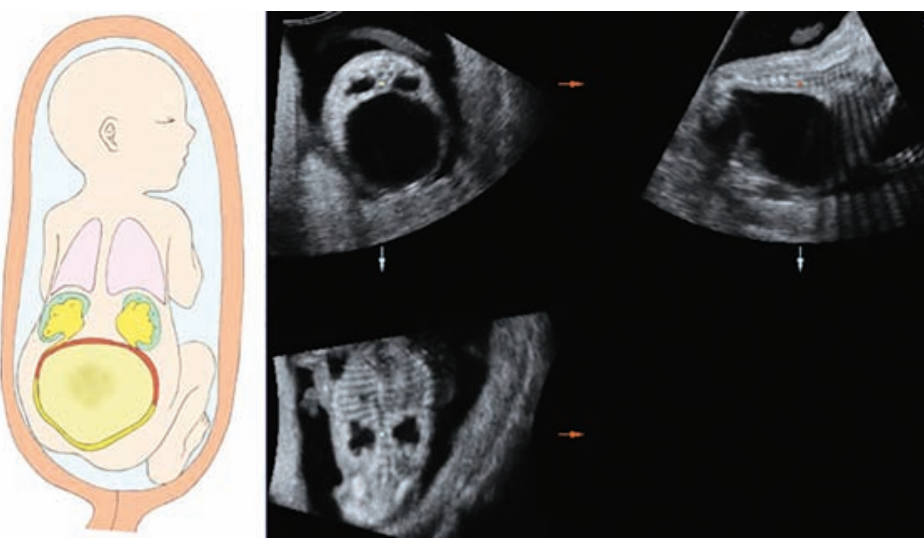

Fig. 40: Megacystis and hydronephrosis due to urethral obstruction at 14 weeks. Multiplanar image. Bilateral hydronephrosis and enlarged bladder is demonstrated

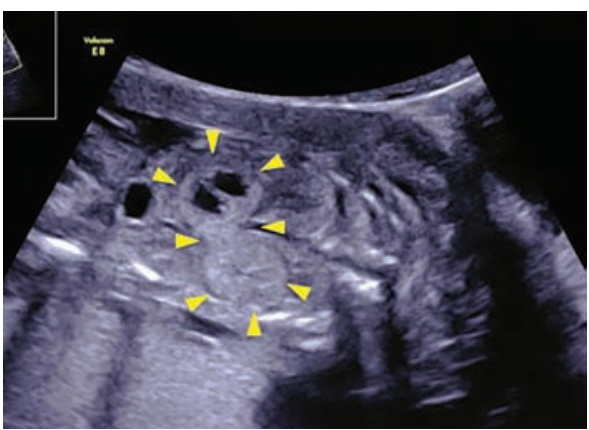

Fig. 41: Horseshoe kidney at 19 weeks. 2D coronal image showing fused bilateral kidneys (arrowheads)
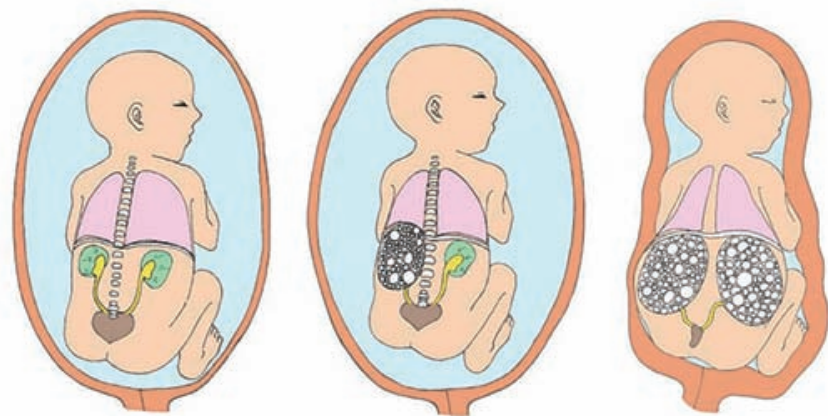

Fig. 43: Schematic picture of normal urinary tract and Multicystic kidney. Left; Normal kidneys, ureters, and bladder. Middle; Unilateral multicystic kidney. The amniotic fluid quantity is normal. Right; Bilateral multicystic kidneys with severe oligohydramnios

bilateral MCDK is lethal anomaly, which causes significant reduction of urine and severe oligohydramnios. Figure 45 demonstrates development of renal multicysts between 15 and 18 weeks of gestation. Thus, in the early pregnancy, cysts are not conspicuous but during the early second trimester, cysts are increasing in size. Fetal MCDK occasionally decreased its size during pregnancy and it is reported that MCDK size tends to decrease during the

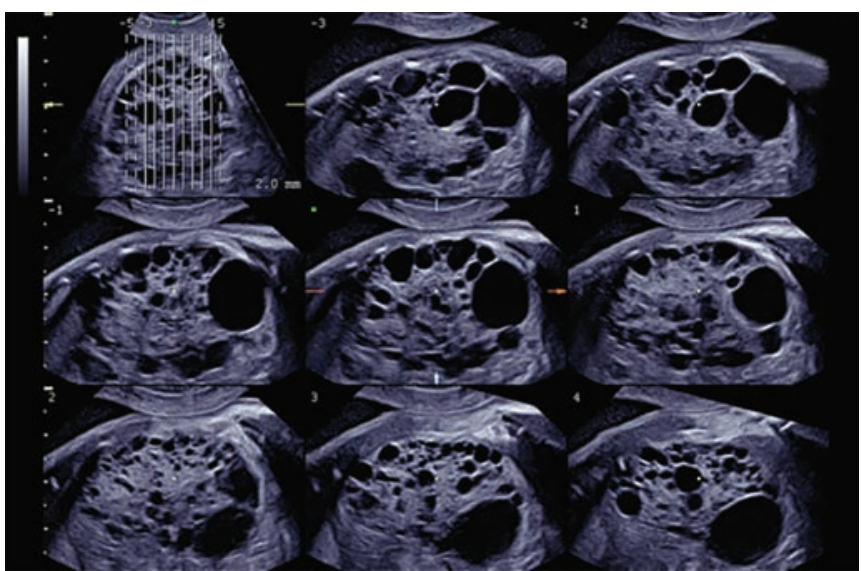

Fig. 44: Multicustic dysplastic kidney (MCDK) at 22 weeks. Tomographic ultrasound image of unilateral MCDK. Note the numerous intrarenal cysts in different size are demonstrated

first 30 postnatal months. ${ }^{37}$ Bladder extrophy as shown in Figure 46 is rarely seen by ultrasound. A vesicoallantoic cyst is a single communicating cavity consisting of an umbilical cord cyst and the fetal urinary bladder. ${ }^{38,39}$ The communication between the allantois and urachus usually closed during the early stage of gestation and 


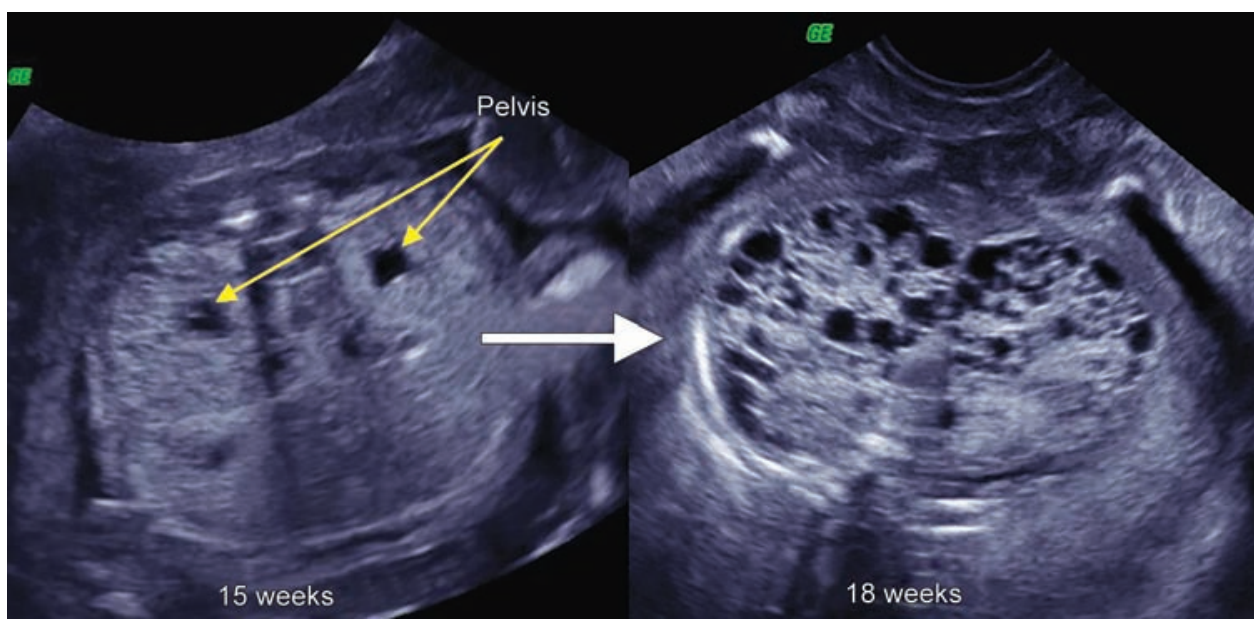

Fig. 45: Bilateral MCDK at 18 weeks. Left; 2D axial image at 15 weeks of gestation. At this stage, renal pelvis was visible. Both kidneys are larger than normal and very tiny numerous cystic formation is visible in the kidney. Right; At 18 weeks, multiple cysts are clearly visible in both kidneys

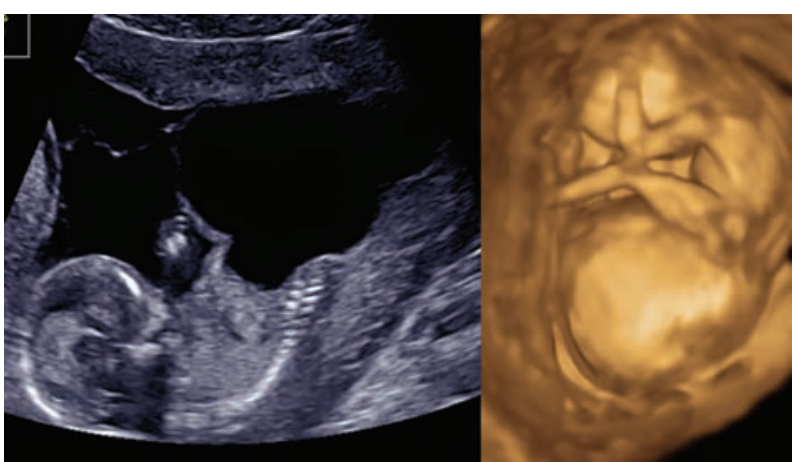

Fig. 46: Bladder extrophy at 15 weeks of gestation. Left; 2D sagittal image. Huge bladder is demonstrated. Right; 3D reconstructed image. Fetus is on the balooning bladder

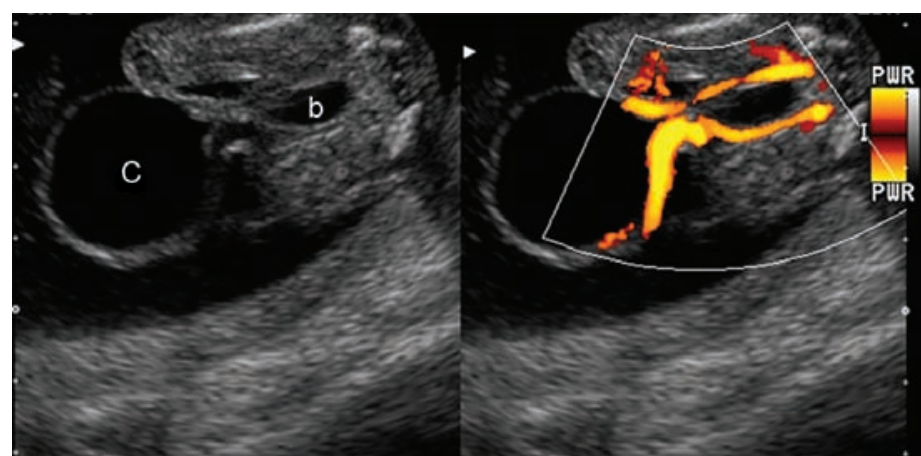

Fig. 47: Vesicoallantoic cyst at 16 weeks of gestation. Left; The extracorporeal cyst (c) is connected with bladder (b). Right; Power Doppler image. Two umbilical arteries are visible along with bladder and allantoic cyst
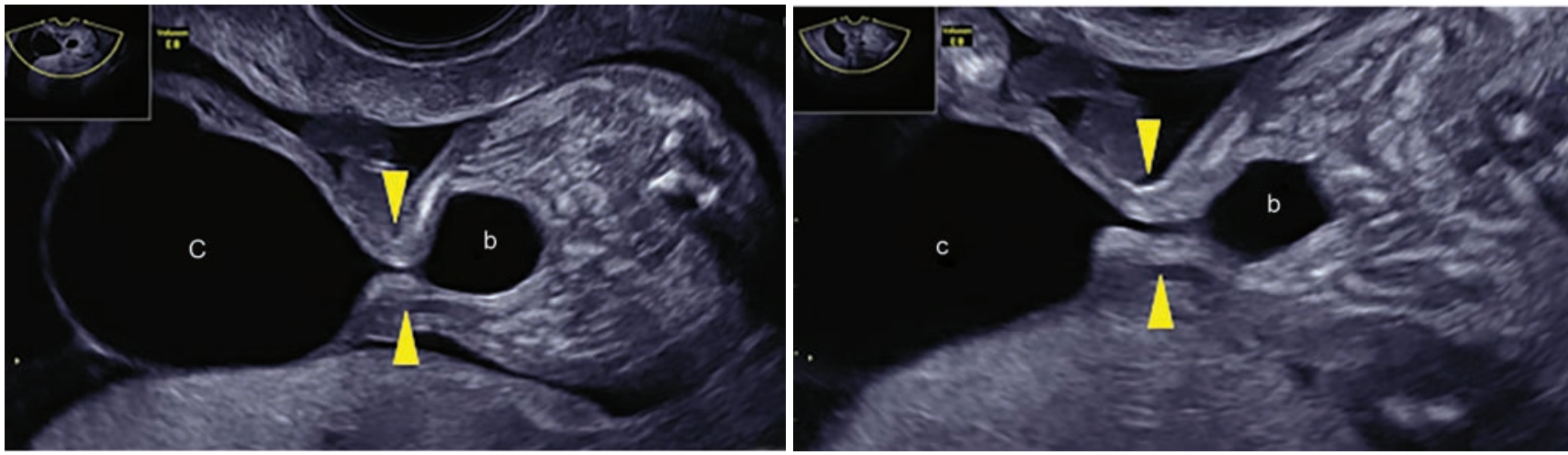

Fig. 48: Vesicoallantoic cyst at 17 weeks of gestation. Left; The extracorporeal cyst (c) is connected with bladder (b). Right; The bladder and cyst size change because of outflow of urine from bladder to the cyst. Note the dynamic change of the urachus (arrowheads)

when this communication fails to disappear, the fetal urinary bladder, urachus, and allantois form a single communicating cavity filled with fetal urine. Figures 47 and 48 show the vesicoallantoisc cyst at 16 and 17 weeks of gestation. Bilateral umbilical arteries along with bladder wall and allantoic cyst provesa single communi- cating cavity (Fig. 47). Occasionally, the dynamic change of the urachus and the bladder and cyst size change are seen (Fig. 48) because of outflow of urine from bladder to the cyst. Maldeveloped external genitalia as shown in Figure 49 is rarely seen in cases with various anomalies or as a single finding. 

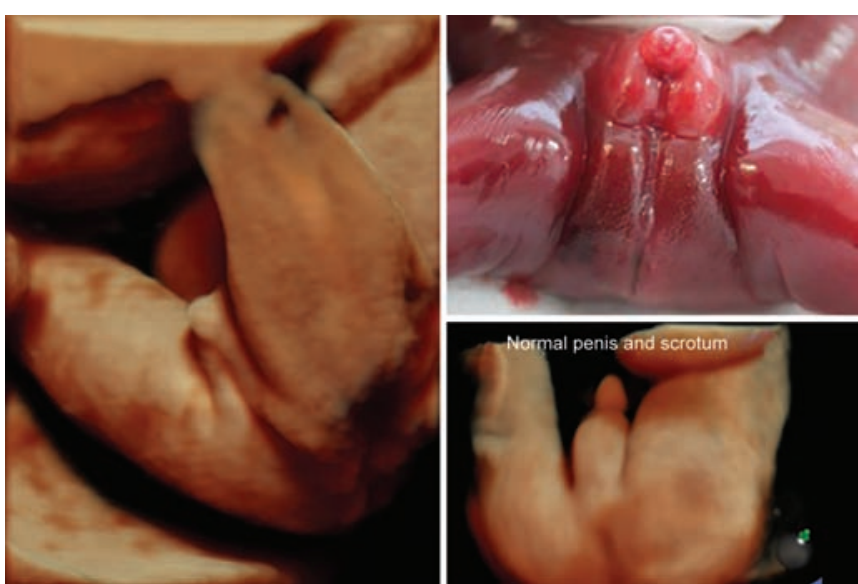

Fig. 49: Hypoplastic external genitalia at 19 weeks. Left; Hypoplastic penis and scrotum is demonstrated in a case of multiple anomalies. Right upper; Genitalia of the aborted fetus at 21 weeks (Postmortum picture by courtesy: Dr. Hideshi Inoshita, Kagawa Inoshita Hospital, Kagawa, Japan)
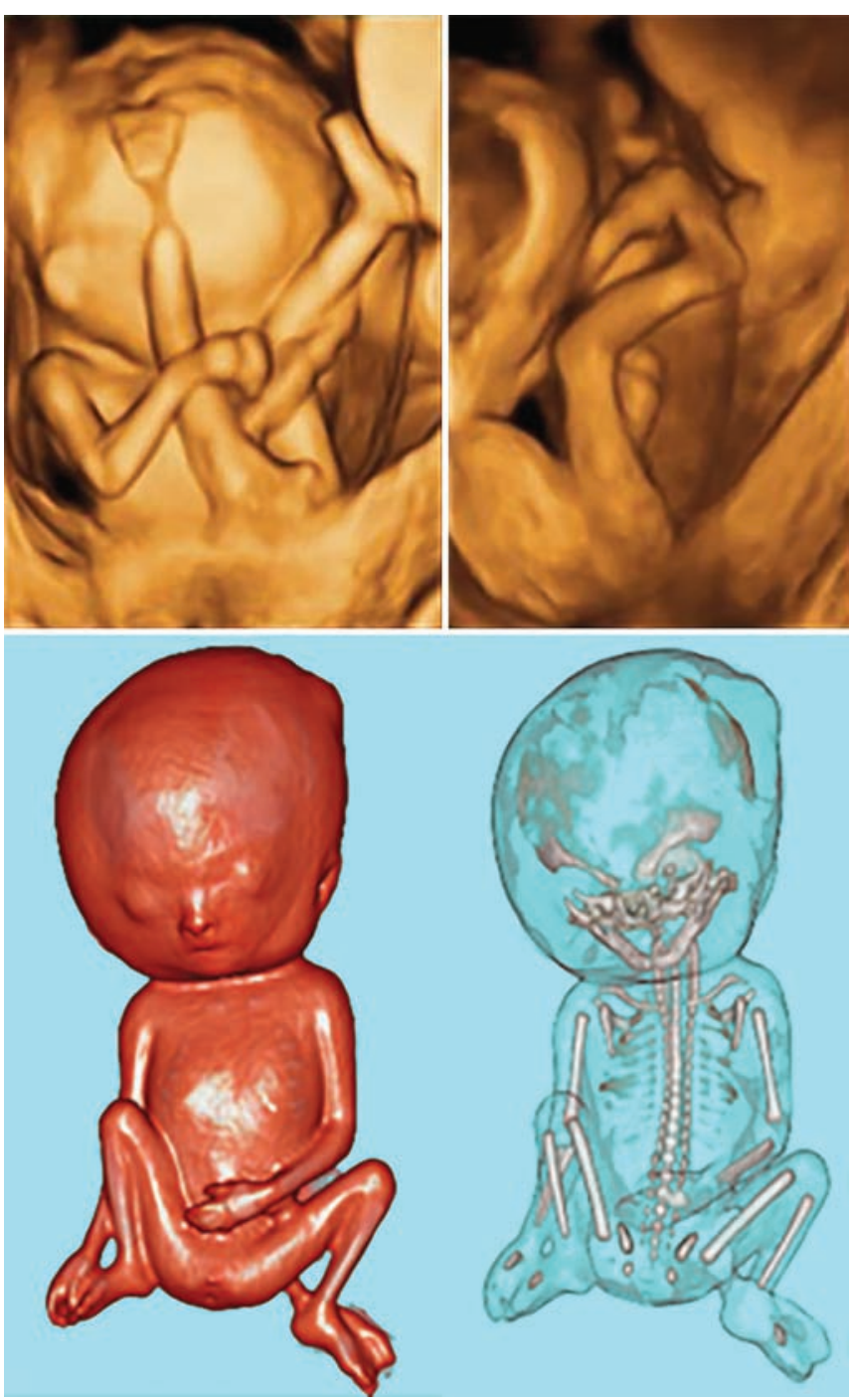

Fig. 50: Thin limbs in a case of triploidy at 17 weeks. (Upper) 3D US reconstructed images. Small for date baby with abnormal proportion, large head, and thin limbs and trunk, is demonstrated. (Lower) Postmortem 3D-CT scan image of surface anatomy (left) and bony structure (right) of the same baby

\section{Limb Abnormalities and Skeletal Dysplasia}

Limb abnormalities can occur as isolated findings or as one component of a syndrome or sequence. However, only $5 \%$ of congenital hand anomalies occur as part of a recognized syndrome. Figure 50 shows typical appearance of triploidy with thin limbs and no other abnormalities. Figure 51 demonstrates 3D ultrasound images and postmortem pictures in a case of lethal pterygium syndrome. Pterygium is used to describe webbing of the skin across the joint. The term means "wing-like." Limb pterygia at birth indicates an abnormal developmental process probably occurring in the first trimester and involving reduced mobility of the webbed limb. Prenatal diagnosis in the first trimester was reported ${ }^{40}$ Figure 52 shows unilateral forearm and thumb abnormality with

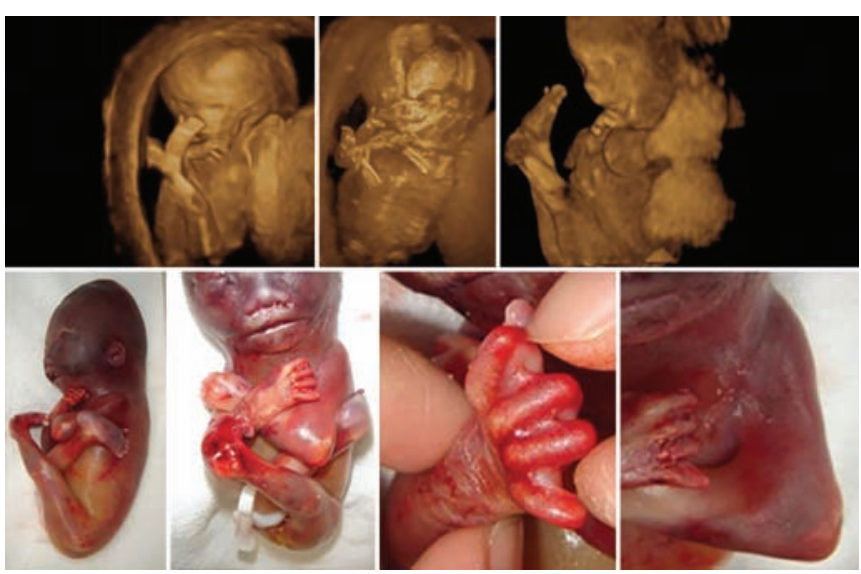

Fig. 51: Lethal pterygium syndrome detected at 14 weeks. (Upper) $3 \mathrm{D}$ reconstructed images. Middle image demonstrated the bony structure by maximum mode. The fetus did not move with the same appearance for weeks. (Lower) Aborted fetus at 20 weeks. The same appearance as prenatal images is seen. The wing-like shoulders and elbows, finger webs are characteristics of this syndrome
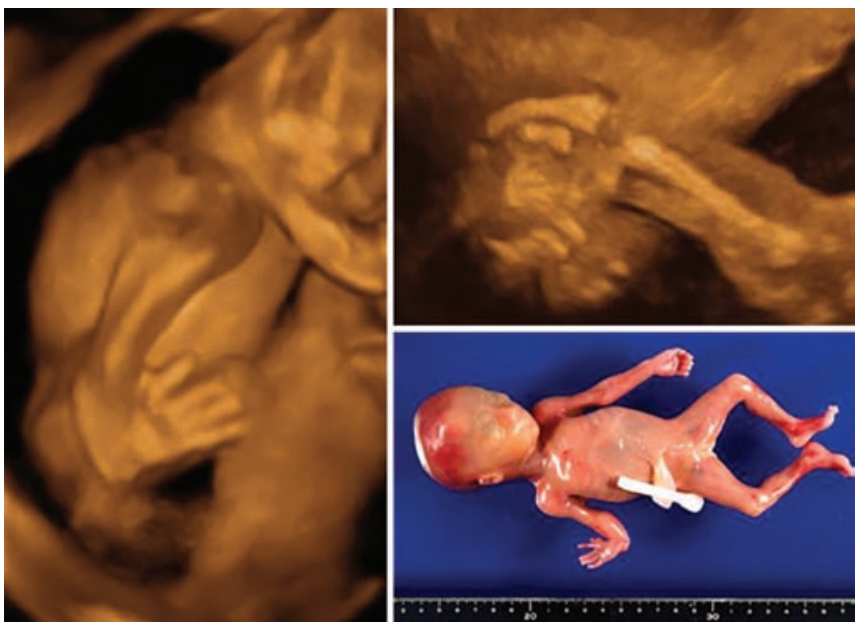

Fig. 52: Right arm abnormality at 18 weeks. (Left) Abnormal appearance of right arm by 3D reconstructed image. Short forearm and thumb abnormality are demonstrated. (Upper right) Maximum mode image of the right arm. Short ulna and extremely short radius are clearly demonstrated. (Lower right) (Postmortem appearance of the aborted fetus, by courtesy: Dr. H. Takemura, Kosaka Women's Hospital, Higashiosaka, Japan). Partial chromosomal abnormality was confirmed 
no other abnormalities in a case of partial chromosomal abnormality.

Genetic disorders involving the skeletal system arise through disturbances in the complex processes of skeletal development, growth, and homeostasis and remain a diagnostic challenge because of their variety. The Nosology and classification of genetic skeletal disorders provides an overview of recognized diagnostic entities and groups them by clinical and radiographic features and molecular pathogenesis. As many as 456 different conditions were included and placed in 40 groups defined by molecular, biochemical, and/or radiographic criteria. ${ }^{41}$ Figure 53 demonstrates two cases of thanatophoric dysplasia (FGFR3 chondrodysplasia) at 19 and 20 weeks. Figures 54A to D shows prenatal diagnosis of severe type of collagenopahty at 20 weeks and Figures 55 and 56 demonstrate fatal dysplasia of osteogenesis imperfecta at 16 and 20 weeks by ultrasound and 3D-CT.

Clubfoot (Figs 57 and 58) is seen bilaterally or unilaterally, as a single finding or as an association with spina bifida or other congenital abnormalities. Figure 59 show rare finding of edematous foot. Three-dimensional ultrasound can demonstrate finger/toe abnormality in detail. Overlapping fingers (Fig. 60), polydactyly (Figs 61 to 63), syndactyly (Figs 64 and 65), clinodactyly (Fig. 66), amputation of fingers (Fig. 67) sandal gap (Fig. 68), and cleft hand/toe
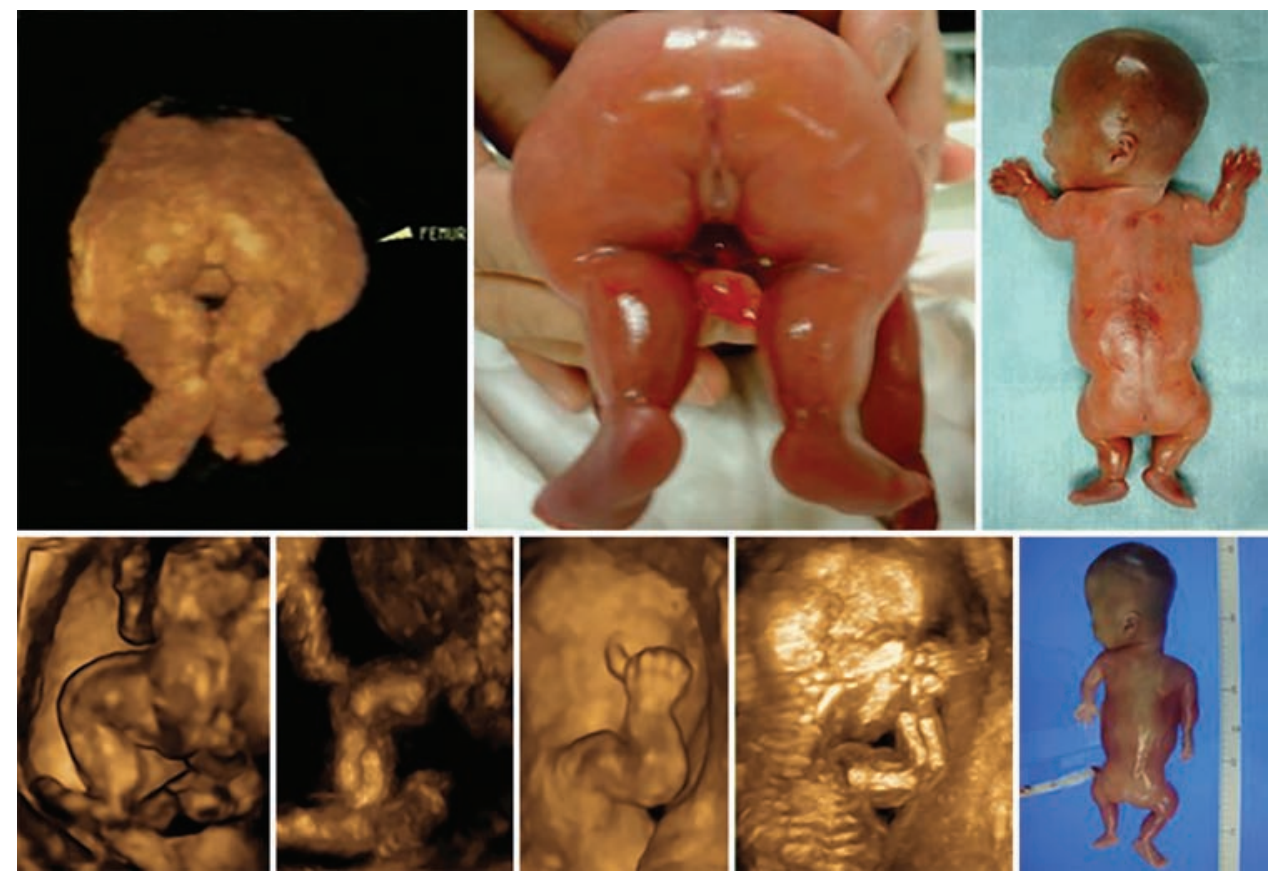

Fig. 53: Thanatophoric dysplasia at 19 weeks. Three-dimensional reconstructed images and postmortem appearance of two cases (upper and lower cases) with short limbs and abnormally curved femurs, are shown
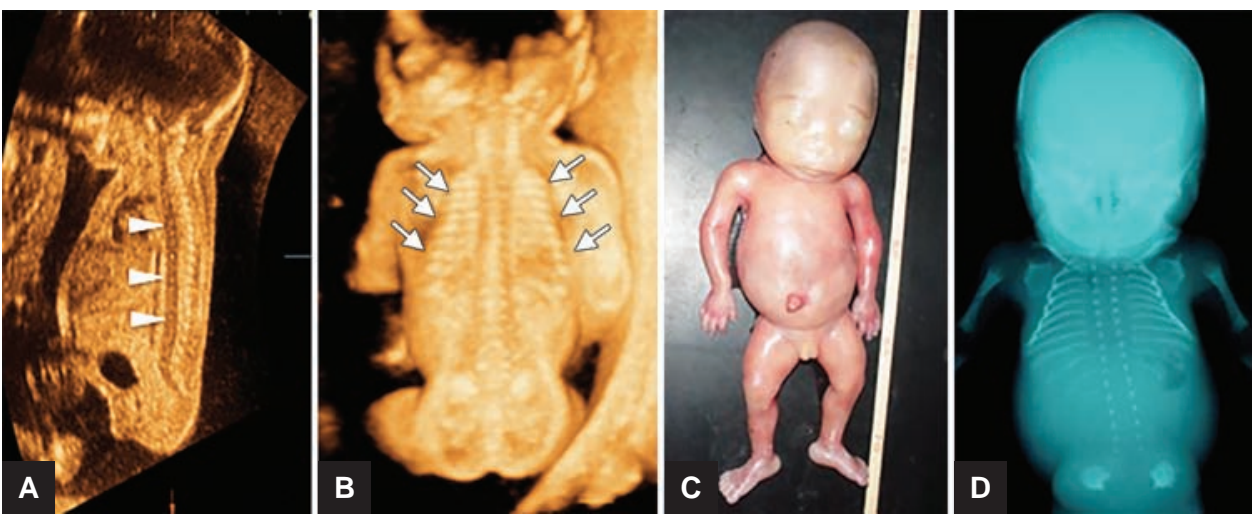

Figs 54A to D: Short limb, hypoplastic vertebral body with micrognathia seen at 20 weeks. (A) Sonographic image of the fetal body in the sagittal section. Vertebral bodies are not visible (arrowheads); (B) three-dimensional maximum mode in the coronal section. Small thorax is estimated from the shape of ribs (arrows); (C) macrographic picture of the aborted fetus at 21 weeks. Micrognathia, short trunk, prominent heals are visible; and (D) postmortum X-ray image. Vertebral bodies are not demonstrated. The same appearance of ribs as prenatal 3D ultrasound is seen. This case was confirmed as severe type of collagenopathy by postmortum genetic examination 

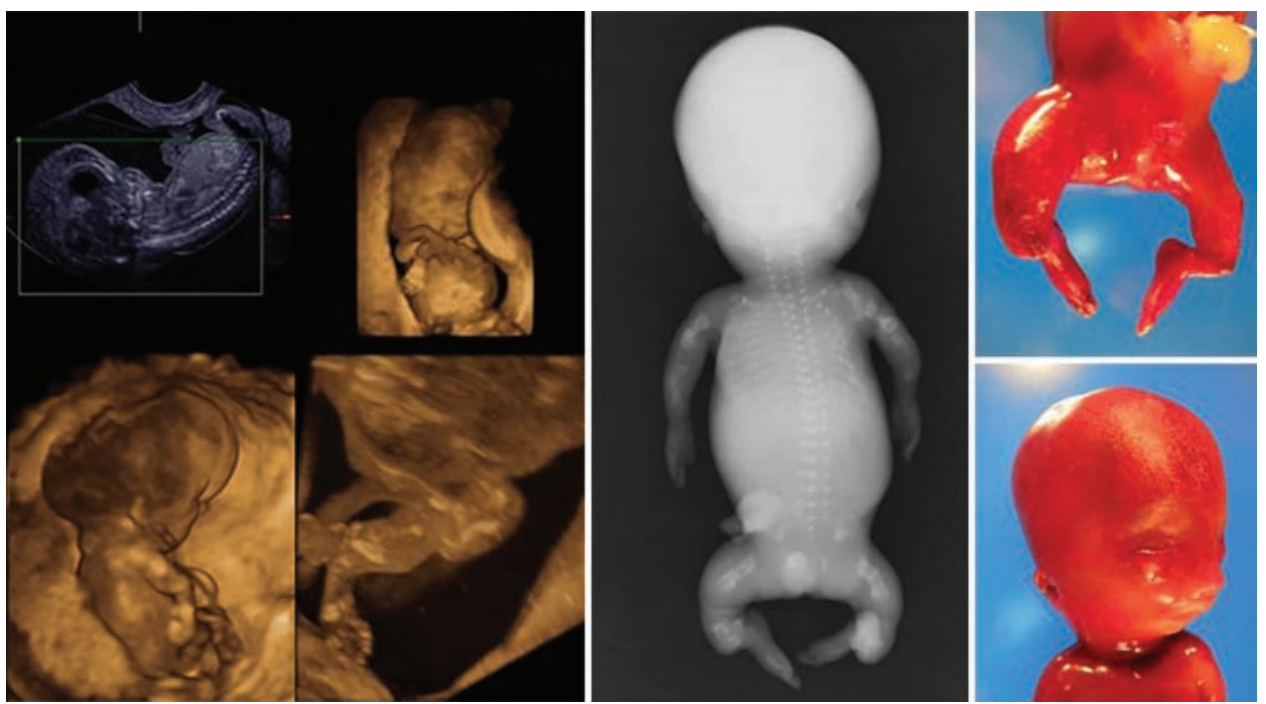

Fig. 55: Severe osteogenesis imperfecta at 16 weeks of gestation. Left 4 images; 3D images at 16 weeks. Abnormally deformed arm is detected (arrows). The long bone developmet was extremely poor (arrowheads). Middle; X-ray image of aborted fetus. Right pictures; Aborted fetus (Courtesy: Dr. Takemura, Kosaka Women's Hospital, Osaka, Japan). Molecular genetic exam showed new mutation of COL1A1 (Courtesy: Prof. Hasegawa, Dept. of Pediatrics, Keio University, Tokyo, Japan)
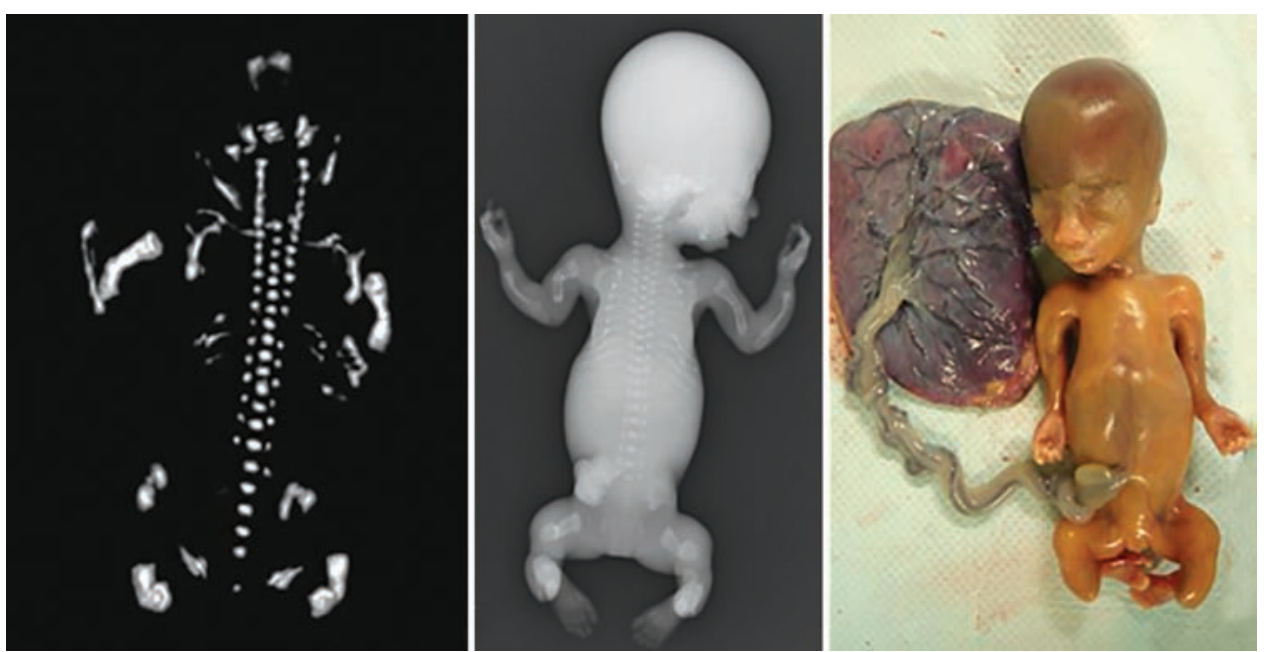

Fig. 56: Osteogenesis imperfecta (OI), fetal 3D-CT, and postmortem findings. Left; Fetal 3D-CT image at 20 weeks. Cranial bones were not visualized and short/curved limb bones with hypoplastic vertebral bones indicated OI. Middle; Postmortum X-ray. Prenatal findings were confirmed. Right; (Macroscopic picture by courtesy: Dr. Hideo Takemura, Kosaka Women's Hospital, Osaka, Japan). In this case, COL1A1gene mutation was confirmed by Prof. Hasegawa, Dept. of Pediatrics, Keio University, Tokyo, Japan
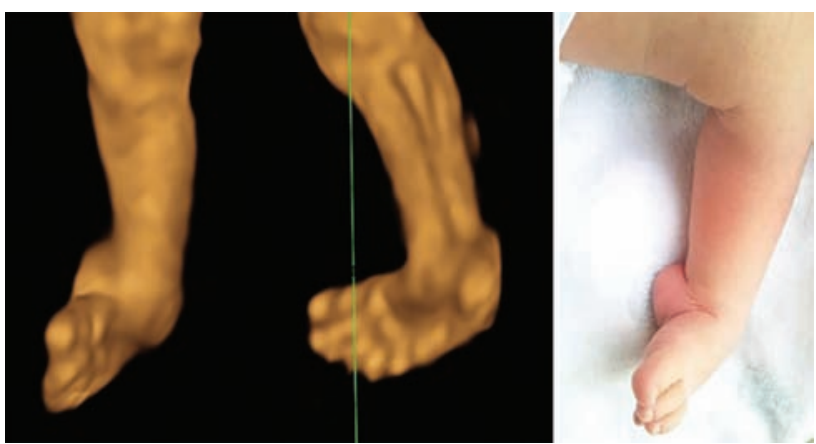

Fig. 57: Clubfoot at 22 weeks of gestation. Left and middle; 3D reconstructed images. Right; Postnatal picture

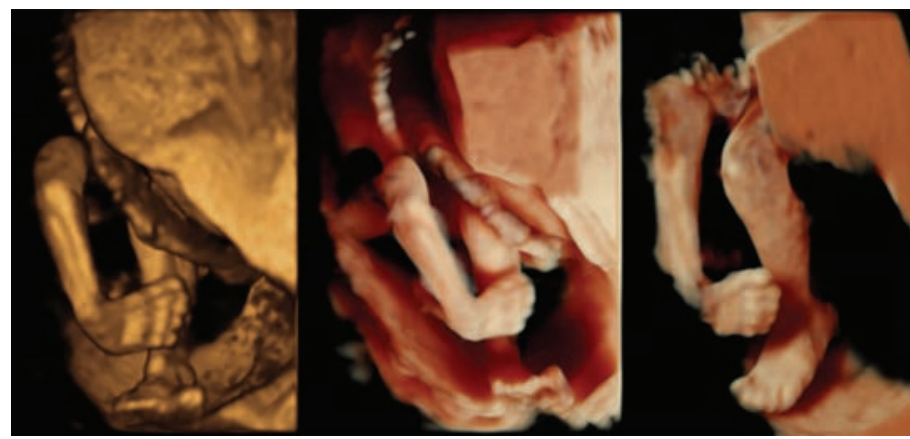

Fig. 58: Unilateral (right side) clubfoot at 18 weeks of gestation. Left; conventional 3D images, Middle and Right; HDlive images 


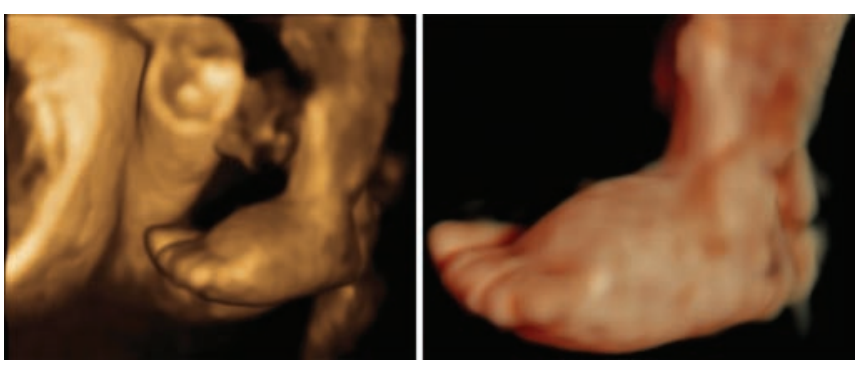

Fig. 59: Edematous left foot at 26 weeks. Left; 3D image. Right; HDlive image. In the first trimester, no increased NT and no abnormalities are seen. The only abnormal finding was left side foot edema at 26 weeks. Although the fetus moved actively and no abnormal sign was found at 26 weeks, sudden intrauterine fetal demise occurred at 33 weeks of gestation

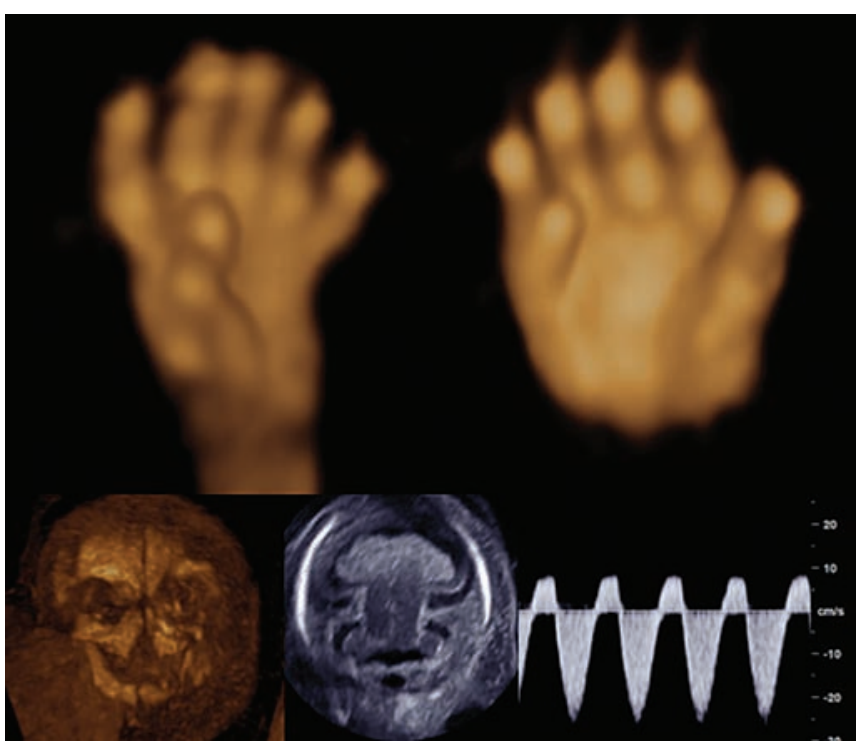

Fig. 61: Polydactyly at 14 weeks. Bilateral polydactyly is clearly demonstrated in upper figures. This case has cleft palate (lower left), holoprosencephaly (lower middle) and umbilical artery reversed flow
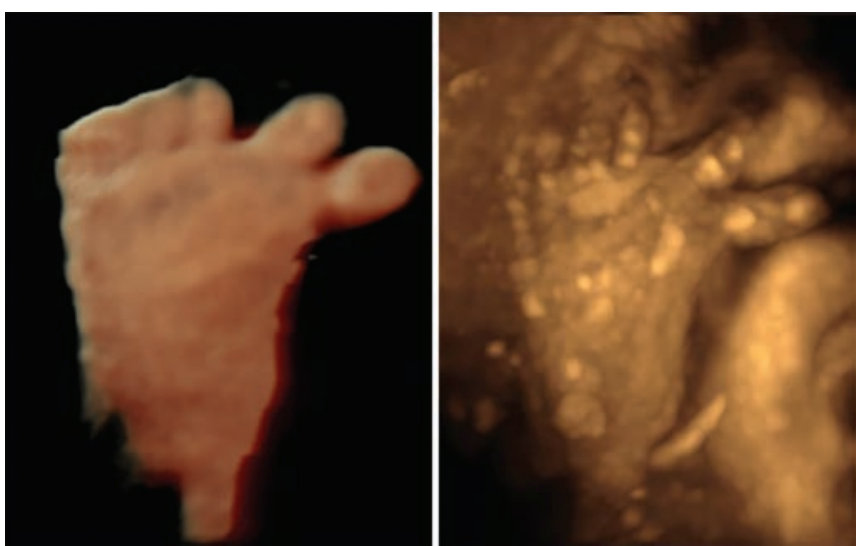

Fig. 63: Polydactyly of the toe at 33 weeks of gestation. Left; HDlive image. Right; Maximum mode image

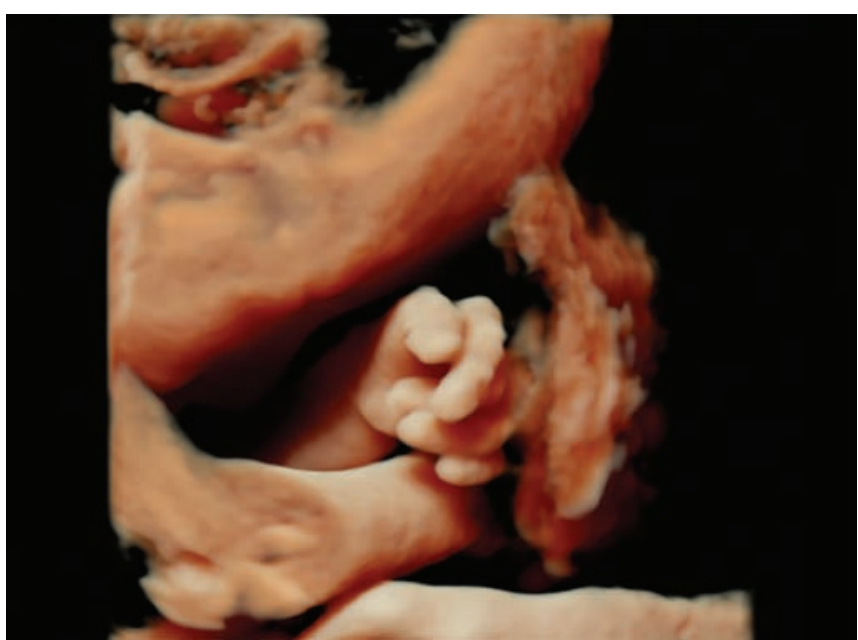

Fig. 60: Overlapping fingers in a case of trisomy 18 at 18 weeks. Typical appearance of overlapping fingers often seen in trisomy 18

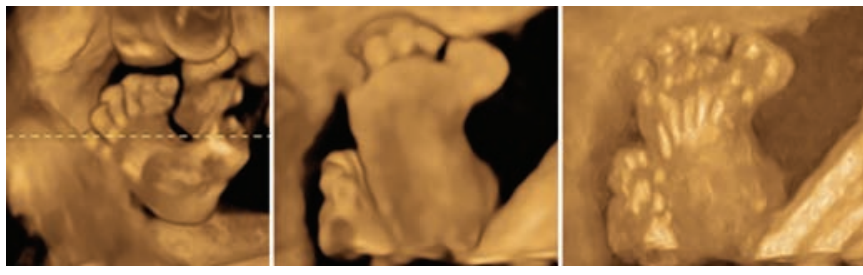

Fig. 62: Polydactyly/syndactyly at 19 weeks. Three-dimensional reconstructed images of the right toe. The first big toe is demonstrated in the left and middle figures. The right figure clearly shows six toe bones

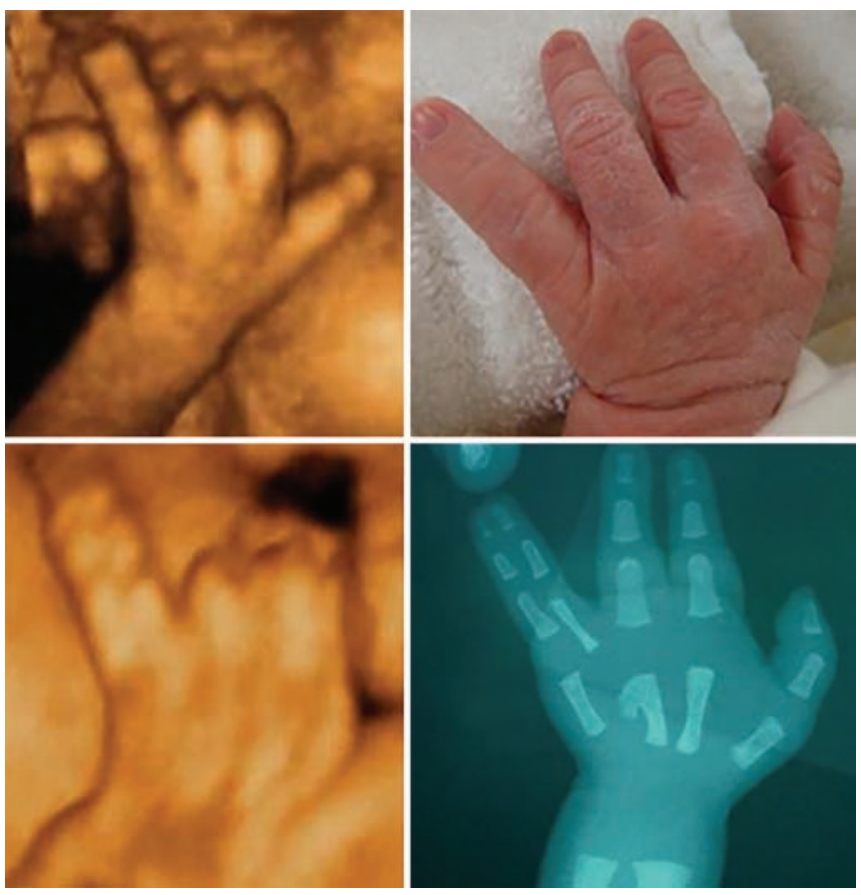

Fig. 64: Syndactyly (single finding) at 28 weeks. (Left) threedimensional reconstructed images of the left hand. The forth and fifth fingers are almost the same size and abnormally stretched together. (Upper right) Postnatal hand appearance. (Lower right) Postnatal X-ray image 

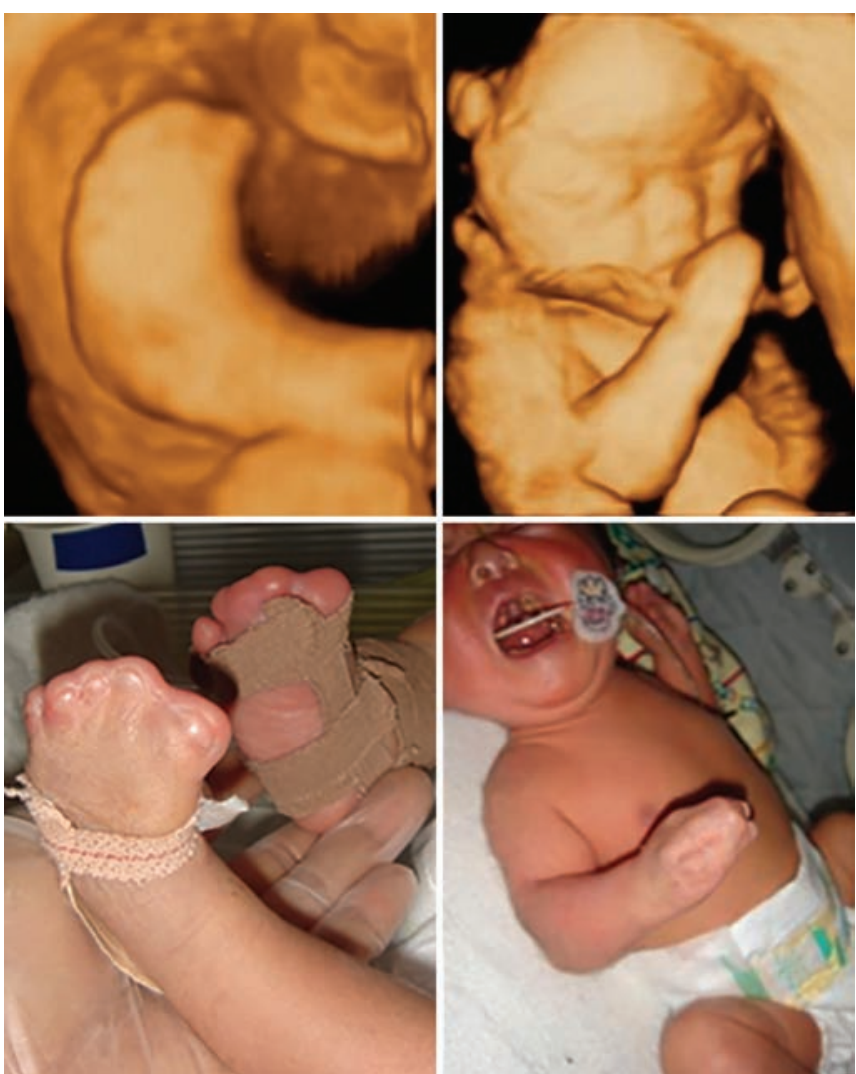

Fig. 65: Syndactyly in a case of Apert syndrome at 31 weeks (Upper) 3D reconstructed images of the foot and hand. All of toes and fingers are sticked together. (Lower) Postnatal appearance of foot and hand. The same appearance as prenatal imaging is seen

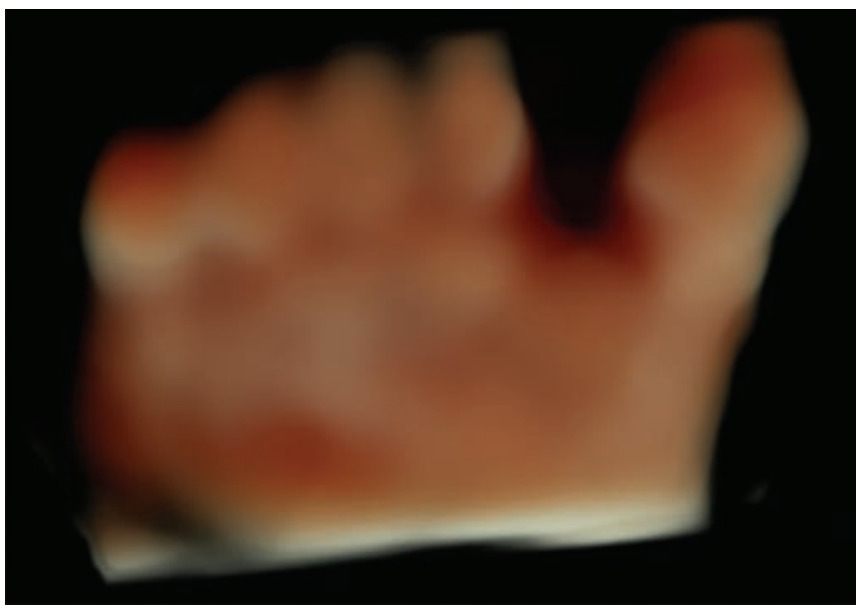

Fig. 68: Sandal gap at 24 weeks. Sandal gap is often seen in Down's fetuses

(Figs 69 to 71) are clearly seen by 3D ultrasound during pregnancy. Thumb abnormality, especially adducted thumb, is one of the important signs for assessment of fetal brain development. ${ }^{42,43}$ Genetic hydrocephalus or brain abnormalities, which is strongly related to L1CAM gene, are associated with adducted thumbs ${ }^{44,45}$ as shown in Figure 72. Limb contracture occasionally seen as one of neurological findings is demonstrated in Figures 73 and 74 .

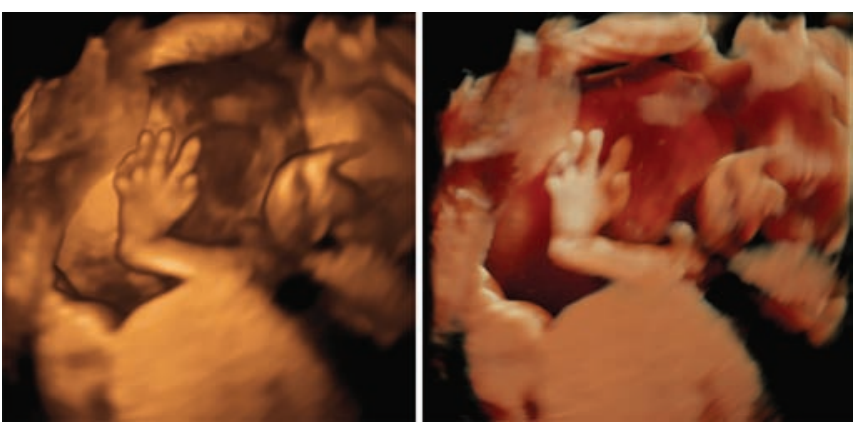

Fig. 66: Clinodactyly seen in a case of Down's syndrome at 19 weeks of gestation. Left; conventional 3D image, Right; HD live image. The 5th finger clinodactyly is well demonstrated

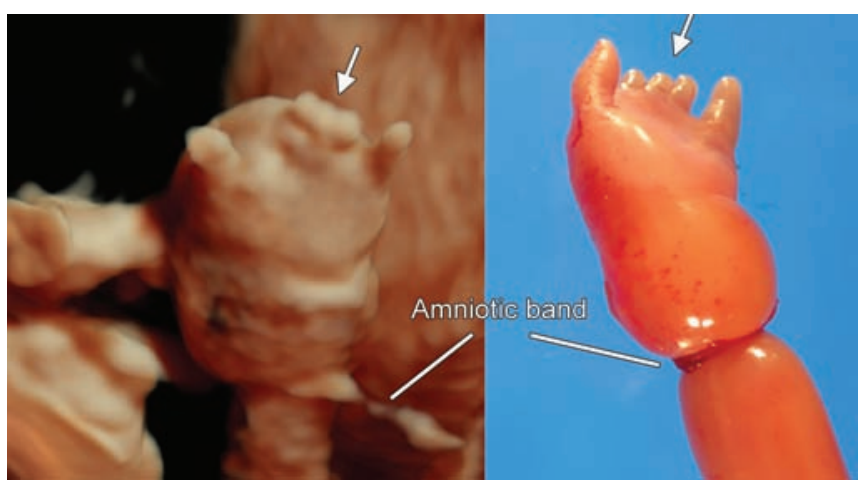

Fig. 67: Amputation of fingers in a case of amniotic band syndrome at 16 weeks of gestation. Left; 3D HD live image. Edematous left forearm/hand due to amniotic band. Amputation of 2,3,4 digits is depicted (arrow). Right; The left arm of the aborted fetus

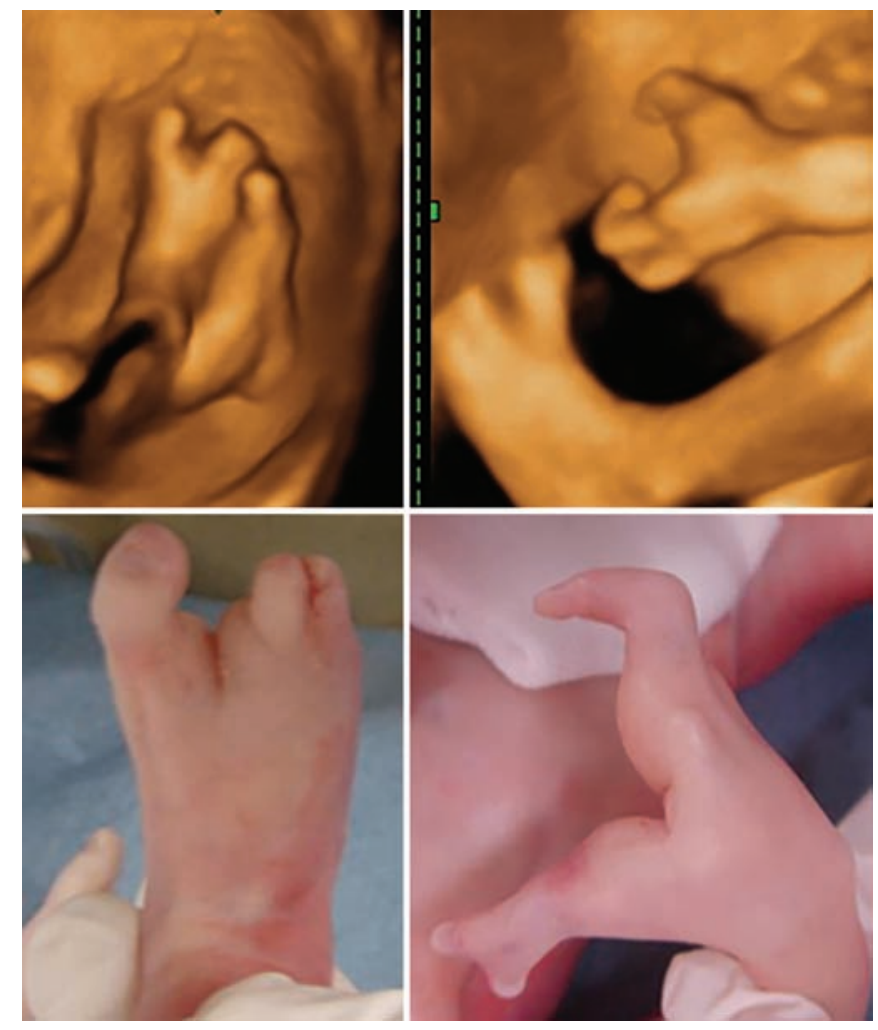

Fig. 69: Cleft foot and cleft hand, Oligodactyly/syndactyly at 28 weeks. (Upper) 3D reconstructed images of the foot and hand. (Lower) Postnatal appearance 


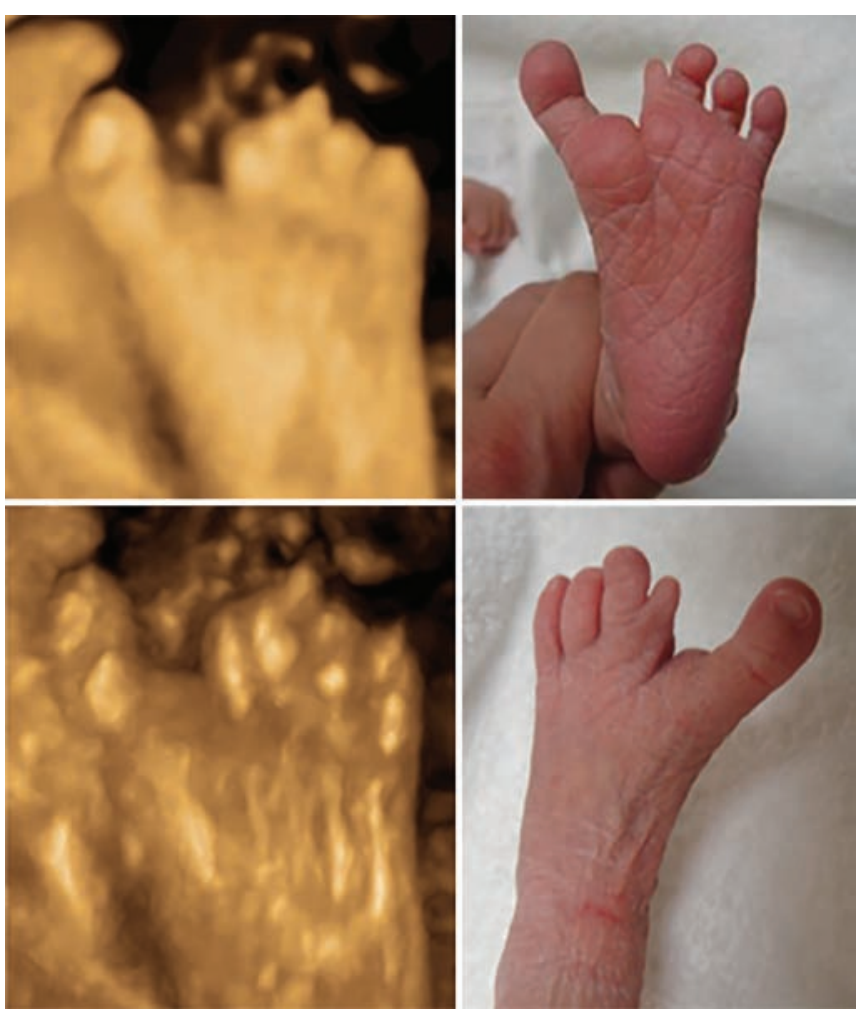

Fig. 70: Cleft foot with toe dysplasia at 35 weeks. (Upper left) 3D reconstructed image. (Lower left) Maximum mode. (Right) Postnatal appearance
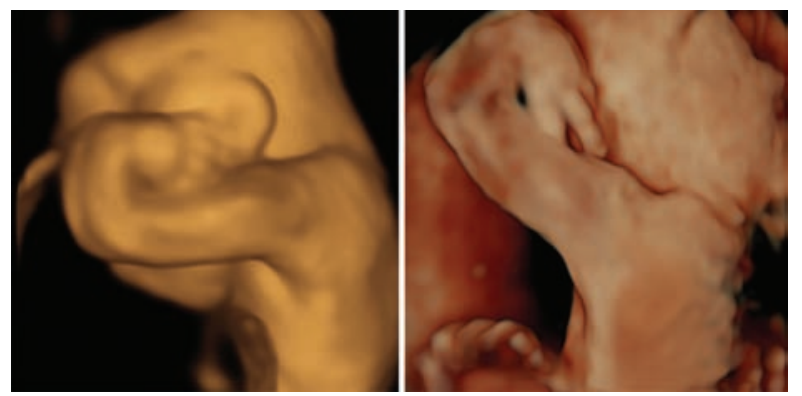

Fig. 73: Short forearm with wrist contracture at 24 weeks of gestation. Left; 3D image, Right; HD live image. Shoulder joint was movable but elbow and wrist was contracted. Chromosome was normal

\section{CONCLUSION}

This article reviews and illustrates the power of highresolution 3D ultrasound in the definition of normal fetal anatomy as well as in the identification of congenital anomalies. The advances of 3D ultrasound in the past decade have been remarkable and contributed to the field of embryology, fetal physiology, and pathology. Further researches by 3D ultrasound will bring more accurate and detailed prenatal diagnosis for better prenatal care.

\section{ACKNOWLEDGMENTS}

Authors thank members of Global Ultrasound and Information Technologies and Women's Health care and Specialty of General Electrics Health care (Milwaukee, USA) for
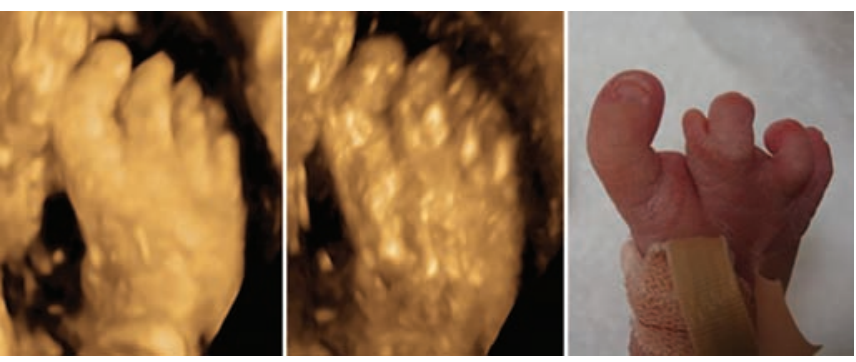

Fig. 71: Cleft foot with toe dysplasia and 1st toe contracture at 35 weeks (same case as Fig. 70). (Left) 3D reconstructed image. (Middle) Maximum mode. (Right) Postnatal appearance
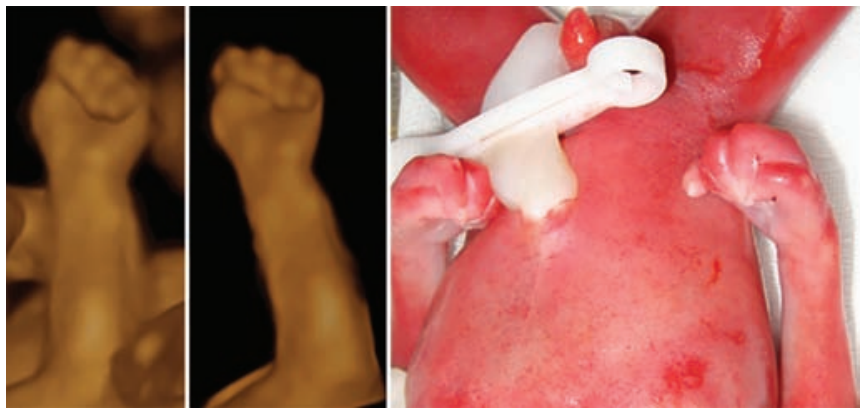

Fig. 72: Adducted thumbs in a case of genetic hydrocephalus. (Left and middle) 3D reconstructed images of adducted thumb. (Right) Postmortem appearance of clenched hands with adducted thumbs. This case is complicated with hydrocephalus, partial agenesis of the corpus callosum. Postmortem genetic test revealed L1CAM disorder
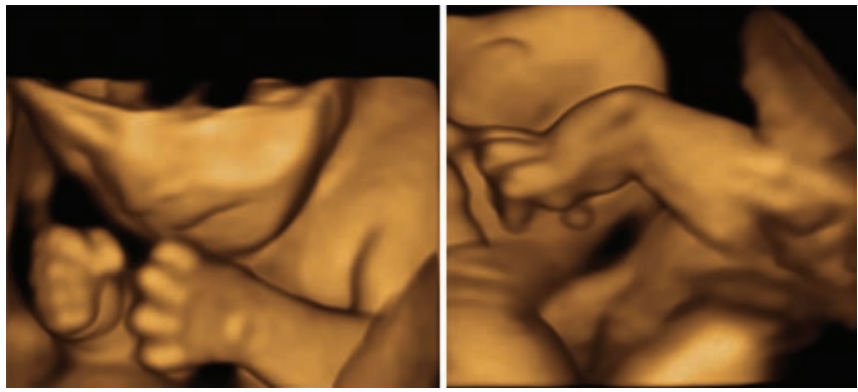

Fig. 74: Hypertonic limb contracture at 26 weeks of gestation. 3D images show hypertonic fingers and wrist. The fetus never unclenched hands throughout pregnancy. Postnatal rehabilitation has improved gradually the limb movements

their technical support and collaboration in 3D ultrasound technology.

\section{REFERENCES}

1. Grigore M, Cojocaru C, Lazar T. The role of HD live technology in obstetrics and gynecology, present and future. Donald School J Ultrasound Obstet Gynecol 2014;8(3):234-238.

2. Bonilla-Musoles F, Raga F, Castillo JC, Bonilla F Jr, Climent MT, Caballero O. High definition Real-Time Ultrasound (HDlive) of embryonic and fetal malformations before week 16. Donald School J Ultrasound Obstet Gynecol 2013 Jan-Mar;7(1):1-8.

3. Nebeker J, Nelson TR. Imaging of sound speed reflection ultrasound tomography. J Ultrasound Med 2012 Sep;31(9): 1389-1404

4. Kurjak A, Pooh RK, Merce LT, Carrera JM, Salihagic-Kadic A, Andonotopo W. Structural and functional early human 
development assessed by three-dimensional and fourdimensional sonography. Fertil Steril 2005 Nov;84(5):1285-1299.

5. Pooh RK, Shiota K, Kurjak A. Imaging of the human embryo with magnetic resonance imaging microscopy and highresolution transvaginal 3-dimensional sonography: human embryology in the 21st century. Am J Obstet Gynecol 2011 Jan;204(1):77.e1-77.e16.

6. Pooh RK. 3D sonoembryology. Donald School J Ultrasound Obstet Gynecol 2011;5(1):7-15.

7. Pooh RK. Early detection of fetal abnormality. Donald School J Ultrasound Obstet Gynecol 2013;7(1):46-50.

8. Pooh RK, Kurjak A. 3D/4D sonography moved prenatal diagnosis of fetal anomalies from the second to the first trimester of pregnancy. J Matern Fetal Neonatal Med 2012 May;25(5):433-455.

9. Kagan KO, Pintoffl K, Hoopmann M. First-trimester ultrasound images using HDlive. Ultrasound Obstet Gynecol 2011 Nov;38(5):607.

10. Hata T, Hanaoka U, Tenkumo C, Sato M, Tanaka H, Ishimura M. Three- and four-dimensional HDlive rendering images of normal and abnormal fetuses: pictorial essay. Arch Gynecol Obstet 2012 Dec;286(6):1431-1435.

11. Pooh RK, Kurjak A. Novel application of three-dimensional HDlive imaging in prenatal diagnosis from the first trimester. J Perinat Med 2015 Mar;43(2):147-158.

12. Pooh RK. First trimester scan by 3D, 3D HDlive and HDlive silhouette/flow ultrasound imaging. Donald School J Ultrasound Obstet Gynecol 2015 Oct-Dec;9(4):361-371.

13. Pooh RK. 'See-through fashion' in prenatal diagnostic imaging. Donald School J Ultrasound Obstet Gynecol 2015;9(2):111.

14. Pooh RK. Brand new technology of HDlive silhouette and HDlive flow images. In: Pooh RK, Kurjak A, editors. Donald School Atlas of advanced ultrasound in obstetrics and gynecology, New Delhi: Jaypee Brothers Medical Publishers (P) Ltd.; 2015. p. 1-39.

15. Teoh M, Meagher S. First-trimester diagnosis of micrognathia as a presentation of Pierre Robin syndrome. Ultrasound Obstet Gynecol 2003 Jun;21(6):616-618.

16. Tsai MY, Lan KC, Ou CY, Chen JH, Chang SY, Hsu TY. Assessment of the facial features and chin development of fetuses with use of serial three-dimensional sonography and the mandibular size monogram in a Chinese population. Am J Obstet Gynecol 2004 Feb;190(2):541-546.

17. Pooh RK. Three-dimensional ultrasound of the fetal brain. In: Kurjak A, editor. Clinical application of 3D ultrasonography. Carnforth (UK): Parthenon Publishing; 2000. p. 176-180.

18. Pooh RK, Pooh KH, Nakagawa Y, Nishida S, Ohno Y. Clinical application of three-dimensional ultrasound in fetal brain assessment. Croat Med J 2000 Sep;41(3):245-251.

19. Blaas HG, Eik-Nes SH, Kiserud T, Berg S, Angelsen B, Olstad B. Three-dimensional imaging of the brain cavities in human embryos. Ultrasound Obstet Gynecol 1995 Apr;5(4):228-232.

20. Blaas HG, Eik-Nes SH, Berg S, Torp H. In-vivo threedimensional ultrasound reconstructions of embryos and early fetuses. Lancet 1998 Oct 10;352(9135):1182-1186.

21. Timor-Tritsch IE, Monteagudo A, Mayberry P. Threedimensional ultrasound evaluation of the fetal brain: the three horn view. Ultrasound Obstet Gynecol 2000 Sep;16(4):302-306.

22. Monteagudo A, Timor-Tritsch IE, Mayberry P. Threedimensional transvaginal neurosonography of the fetal brain: 'navigating' in the volume scan. Ultrasound Obstet Gynecol 2000 Sep;16(4):307-313.
23. Pooh RK, Nagao Y, Pooh KH. Fetal neuroimaging by transvaginal 3D ultrasound and MRI. Ultrasound Rev Obstet Gynecol 2006;6(3-4):123-134.

24. Pooh RK, Pooh KH. Fetal neuroimaging with new technology. Ultrasound Review Obstet Gynecol 2002;2:178-181.

25. Pooh RK. Fetal brain assessment by three-dimensional ultrasound. In: Kurjak A, Kupesic S, editors. Clinical application of 3D sonography. Carnforth (UK): Parthenon Publishing; 2000. p. 171-179.

26. Pooh RK, Pooh KH. Transvaginal 3D and Doppler ultrasonography of the fetal brain. Semin Perinatol 2001 Feb;25(1):38-43.

27. Pooh RK, Pooh KH. The assessment of fetal brain morphology and circulation by transvaginal 3D sonography and power Doppler. J Perinat Med 2002;30(1):48-56.

28. Pooh RK, Pooh KH. Fetal ventriculomegaly. Donald school J Ultrasound Obstet Gynecol 2007;2(2):40-46.

29. Pooh RK, Maeda K, Pooh KH. An Atlas of fetal central nervous system disease. Diagnosis and management. London, New York: Parthenon, CRC Press; 2003.

30. Pooh RK. Neuroscan of congenital brain abnormality. In: Pooh RK, Kurjak A, editors. Fetal neurology. New Delhi: Jaypee Brothers Medical Publishers (P) Ltd.; 2009. p. 59-139.

31. Pooh RK. Fetal neuroimaging of neural migration disorder. Ultrasound Clin 2008;3(4):541-555.

32. Blaas HG, Eik-Nes SH, Isaksen CV. The detection of spina bifida before 10 gestational weeks using two- and three-dimensional ultrasound. Ultrasound Obstet Gynecol 2000 Jul;16(1):25-29.

33. Scott RM, Wolpert SM, Bartoshesky LE, Zimbler S, Karlin L. Segmental spinal dysgenesis. Neurosurgery 1988 Apr;22(4): 739-744.

34. Doyle NM, Lally KP. The CDH study group and advances in the clinical care of the patient with congenital diaphragmatic hernia. Semin Perinatol 2004 Jun;28(3):174-184.

35. Daskalakis G, Anastasakis E, Souka A, Manoli A, Koumpis C, Antsaklis A. First trimester ultrasound diagnosis of congenital diaphragmatic hernia. J Obstet Gynaecol Res 2007 Dec;33(6):870-872.

36. Sanz-Cortés M, Raga F, Bonilla-Musoles F. Prenatal diagnosis of congenital cystic adenomatoid malformation using threedimensional inversion rendering: a case report. J Obstet Gynaecol Res 2008 Aug;34(4 Pt 2):631-634.

37. Siqueira Rabelo EA, Oliveira EA, Silva JM, Oliveira DS, Colosimo EA. Ultrasound progression of prenatally detected multicystic dysplastic kidney. Urology 2006 Nov;68(5): 1098-1102.

38. Yoo SJ, Lee YH, Ryu HM, Joo MS, Cheon CK, Park KW. Unusual fate of vesicoallantoic cyst with non-visualization of fetal urinary bladder in a case of patant urachus. Ultrasound Obstet Gynecol 1997 Jun;9(6):422-424.

39. Shukunami K, Tsuji T, Kotsuji F. Prenatal sonographic features of esicoallantoic cyst. Ultrasound Obstet Gynecol 2000 Jun;15(6):545-546.

40. Gundogan M, Fong K, Keating S, Pierre-Louis J, Chitayat D. First trimester ultrasound diagnosis of lethal multiple pterygium syndrome. Fetal Diagn Ther 2006;21(5):466-470.

41. Warman ML, Cormier-Daire V, Hall C, Krakow D, Lachman R, LeMerrer M, Mortier G, Mundlos S, Nishimura G, Rimoin DL, et al. Nosology and classification of genetic skeletal disorders: 2010 revision. Am J Med Genet A 2011 May;155A(5):943-968.

42. Kurjak A, Miskovic B, Stanojevic M, Amiel-Tison C, Ahmed B, Azumendi G, Vasilj O, Andonotopo W, Turudic T, SalihagicKadic A. New scoring system for fetal neurobehavior assessed 
by three- and four-dimensional sonography. J Perinat Med 2008;36(1):73-81.

43. Kurjak A, Tikvica A, Stanojevic M, Miskovic B, Ahmed B, Azumendi G, Di Renzo GC. The assessment of fetal neurobehavior by three-dimensional and four-dimensional ultrasound. J Matern Fetal Neonatal Med 2008 Oct;21(10):675-684.
44. Yamasaki M, Thompson P, Lemmon V. CRASH syndrome: mutations in L1CAM correlate with severity of the disease. Neuropediatrics 1997 Jun;28(3):175-178.

45. Kanemura Y, Takuma Y, Kamiguchi H, Yamasaki M. First case of L1CAM gene mutation identified in MASA syndrome in Asia. Congenit Anom (Kyoto) 2005 Jun;45(2):67-69. 